\title{
Prevalence of depression and burden among informal caregivers of people with dementia: a meta-analysis
}

Rebecca N. Collins ${ }^{\mathrm{a}}$ and Naoko Kishita ${ }^{\mathrm{b}}$

${ }^{a}$ Department of Clinical Psychology, University of East Anglia, Norwich, NR4 7TJ, England, UK; ${ }^{\mathrm{b}}$ School of Health Sciences, University of East Anglia, Norwich, NR4 7TJ, England, UK

Corresponding author:

Qualifications: BSc, MSc

Mailing address: Department of Clinical Psychology, University of East Anglia, Norwich, NR4 7TJ, England, UK

E-mail address: bctalks7@hotmail.com

Contact telephone number: 07872578788 
Depression and burden in caregivers of people with dementia

\begin{abstract}
This meta-analysis examined the prevalence of depression and burden among informal caregivers of people with dementia (PwD) and compared the prevalence of depression between male and female, and spousal and non-spousal, caregivers. The quality of studies was evaluated and moderator variables explored. A search of six electronic databases (PsycARTICLES, PsycINFO, MEDLINE Complete, SCOPUS, Web of Science and ProQuest) was conducted from the first available date to the 31 st October 2017. Inclusion criteria involved observational studies that detailed the prevalence of burden or depression among informal caregivers of PwD. Forty three studies were examined with a total of 16911 participants. The adjusted pooled prevalence of depression was 31.24 per cent $(95 \% \mathrm{CI}$ $27.70 \%$ to $35.01 \%$ ) and burden was 49.26 per cent (95\% CI $37.15 \%$ to $61.46 \%$ ), although heterogeneity among prevalence estimates was high. Depression prevalence estimates differed according to the instrument used and continent in which the study was conducted. The odds of having depression were almost one and a half times higher in female compared to male caregivers. No significant difference was observed between spouses and non-spouses. Most studies had a medium risk of bias. The results indicate a great need within this population for interventions that are effective at reducing burden and depressive symptoms. It therefore appears imperative for dementia services that are not providing interventions targeting these difficulties to do so.
\end{abstract}

Keywords: carers; depressive symptoms; caregiver-burden; epidemiology. 
Depression and burden in caregivers of people with dementia

\section{Introduction}

The number of people with dementia (PwD) is rising every year. By 2050, there will be approximately 131 million PwD worldwide (Alzheimer's Disease International 2015). It has therefore been perceived as one of the greatest problems facing society in the twentyfirst century (Alzheimer's Society 2014).

The majority of PwD are community-dwelling and cared for by a spouse or an adult child, typically of the female gender (Alzheimer's Research UK 2015). The increasing number of dementia cases means that the number of informal caregivers (unpaid relatives or friends) of PwD is also increasing. Research indicates that informal caregivers of PwD can experience positive benefits from the acquisition of the caregiving role, such as feeling as though family members have come closer together and appraising life as more fulfilling and meaningful (Cohen, Colantonio and Vernich 2002). However, there is an abundance of literature that suggests that the role can lead to the presence of perceived burden (e.g. Chiao, Wu and Hsaio 2015; Brodaty and Donkin 2009) and psychological difficulties. The strongest evidence base is for the presence of depressive symptoms, that are more severe than those found in older adults who are not caregivers (Vitaliano 1997) and caregivers of people without dementia (Pinquart and Sörensen 2003).

\section{Burden}

In this review, 'caregiver burden' (here on referred to as 'burden') is conceptualised as a multidimensional biopsychosocial reaction (Given et al. 2001) that results from the caregiver's perception of the degree to which the care-recipient is dependent upon them and the caregiving role has had a negative impact upon their emotional health, physical health and social or financial status (Zarit, Todd and Zarit 1986). Literature has frequently attempted to distinguish 'objective' from 'subjective' burden, although this distinction still remains 
unclear. The current burden definition is based on that of Zarit, Todd and Zarit (1986) which has been suggested to include 'objective burden' concepts (e.g. physical, social and financial impacts and level of dependency) and 'subjective burden' concepts (e.g. the caregiver's perceptions and the emotional impact of caregiving), and is in line with most of the wellestablished and validated caregiver burden measures (Vitaliano, Young and Russo 1991).

When taking into account this burden definition and the research comparing the experiences of caregivers of people with and without dementia, it becomes clear why caregivers of PwD might perceive greater burden. Caregivers of PwD tend to spend more hours per week on caregiving tasks, assist with a greater number of activities of daily living, report more employment complications and less time for leisure and social activities due to caregiving responsibilities (Ory et al. 1999), and spend more of their own money on caregiving expenses (O’Brien 2016). In addition to this, many PwD display aggressive behaviours, the presence of which increases perceived burden (Ornstein and Gaugler 2012). Interestingly, the higher the burden experienced by caregivers of $\mathrm{PwD}$, the more likely they are to expedite nursing home placement (Gaugler et al. 2005).

Research exploring burden in caregivers of PwD has tended to focus on the relationships between burden and psychological constructs such as depression, and predictors of burden. This has revealed that depressive symptoms and burden are positively correlated with one another (Epstein-Lubow et al. 2008; Medrano et al. 2014). Moreover, that there are significant patient related predictors of burden such as the patients' severity of dementia, behavioural problems or psychological symptoms and extent of personality change, and caregiver related predictors including sociodemographic variables and psychological health (Etters, Goodall and Harrison 2008; Chiao, Wu and Hsaio 2015). These studies have therefore been significant in uncovering the potential difficulties that may be experienced by those with perceived burden and the types of factors that increase a caregiver's vulnerability 
Depression and burden in caregivers of people with dementia

to experiencing perceived burden. However, to our knowledge, there has been no metaanalytic review of the prevalence of burden among informal caregivers of PwD. Determining this would appear vital to further our psychological understanding of this population and help inform the provision of services.

\section{Depression}

Depressive symptoms can include a persistent sadness/low mood, marked loss of interest or pleasure in activities, disturbed sleep, decreased or increased appetite or weight, loss of energy, poor concentration, feelings of worthlessness or guilt and/or suicidal ideation or acts (American Psychiatric Association; APA 2013). To fulfil the Diagnostic and Statistical Manual of Mental Disorders-V (DSM-V) criteria for major depression at least one of the first two symptoms must be present alongside five of the remaining symptoms nearly every day for at least two weeks (APA 2013). There are numerous self-report measures that have been designed to map onto the diagnostic criteria for depression, include specified cutoffs to determine depression, and have been validated in older adult populations. The most frequently used measure in research on caregivers of PwD is the Centre for Epidemiological Studies-Depression (CES-D; Radloff 1977).

Caregivers who have depression typically experience problems in daily functioning and poorer physical health (Gallagher et al. 1989; Cucciare et al. 2010). In addition, a large cross-sectional study of 566 informal caregivers of PwD revealed that approximately 16 per cent had contemplated suicide more than once in the previous year (O'Dwyer et al. 2016). Although a smaller longitudinal study found the prevalence of suicidal thoughts to be substantially lower than this at approximately five per cent (Joling et al. 2018), both studies reported depression to be a risk factor for suicidal ideation. Therefore, at least, depression can compromise a caregivers' ability to effectively maintain their role and, at worst, it can lead to 
suicide; demonstrating why investigating the prevalence of depression among this population is important.

A previous meta-analysis found a moderately significant difference in depressive symptoms between informal caregivers of $\mathrm{PwD}$ and people who were not caregivers (Pinquart and Sörensen 2003). This review however did not evaluate the prevalence of depression among either group. A meta-analysis conducted 13 years ago estimated the pooled prevalence of depressive disorders among informal caregivers of PwD, assessed via interviews based on the DSM-III(-R)/IV (APA, 1980; APA, 1987; APA, 1994) or International Classification of Diseases 10th Revision (ICD-10; WHO 1992). This was found to be approximately five times higher than that of the general population, at 22.5 per cent (Cuijpers 2005). A more recent meta-analysis by Sallim, et al. (2015) estimated the pooled prevalence of depression among caregivers of people with Alzheimer's disease (AD), measured via self-report instruments, to be 34 per cent. However, these reviews included relatively small numbers of studies; ten (Cuijpers 2005) and 13 (Sallim et al. 2015).

A contextual model (Fig 1) by Williams (2005) adapted from that of DilworthAnderson and Anderson (1994) conceptualised the factors that may influence the likelihood of a caregiver of someone with dementia experiencing depression. Among other factors, gender and the relationship to the care-recipient were posited to influence this likelihood.

$<$ insert fig 1 . here $>$

Indeed, one meta-analysis found the prevalence of depression to be higher in female and spousal caregivers of people with AD compared to male and non-spousal caregivers of people with AD, respectively (Sallim et al. 2015). However, this review was limited to caregivers of people with $\mathrm{AD}$ and, due to the extremely small number of included studies in each meta-analysis $(n=3)$ and the lack of assessment of publication bias, findings may not be robust. It is important to note that using meta-analytic approaches to investigate the influence 
of the other contextual factors presented in the adapted model of Williams (2005) on depression would not be appropriate, given that research often presents these factors as summary data and conducting moderator analyses on such data would introduce aggregation bias (Harbord 2010).

There are many psychological interventions that are being delivered to and adapted for informal caregivers of PwD, such as Compassion-Focussed Therapy (Collins, Gillian and Poz 2018) and Mindfulness Based Stress Reduction (e.g. Hoppes et al. 2012). Determining the current prevalence of burden and depression is important to quantify the need for such programmes and the requirement to develop, adapt, or change the availability of, existing treatments to fulfil the needs of this client group, and so help delay and reduce rates of transition into care homes (Alzheimer's disease International 2013; Gaugler et al. 2005).

The study aimed to address the gaps in the literature on burden and depression by conducting a current comprehensive meta-analysis with the following objectives:

(1) To quantify the prevalence of burden and depression among informal caregivers of PwD.

(2) To compare the prevalence of depression among female and male caregivers and spousal and non-spousal caregivers.

(3) To explore moderator variables including the methodological quality

\section{Method}

The meta-analysis adhered to the Preferred Reporting Items for Systematic Reviews and Meta-Analyses guidelines (PRISMA; Moher et al. 2009).

\section{Eligibility Criteria}

Articles were included if they were written in English or Japanese, as both authors are fluent in English and the second author fluent in Japanese, and used observational study 
designs (see Munn et al. 2014) including prospective and retrospective longitudinal cohort studies, case-control studies, cross-sectional studies and studies that analysed baseline data from other studies of randomized controlled trials (RCTs). All other study designs were excluded, such as experimental studies, qualitative studies, and review articles.

The population studied were informal caregivers of PwD. Studies involving caregivers of people without dementia or professional caregivers (e.g. paid support workers) were excluded. There were no limitations on the gender or age of the caregivers, the dementia type of the care-recipients, the setting or time spent as a caregiver. Studies were included if they sought to recruit a representative sample of its population. Studies were therefore excluded if they recruited only caregivers with specific mental or physical health difficulties, or they actively excluded caregivers experiencing a depressive episode.

Similar to the meta-analyses of Krebber et al. (2014) and Wang et al. (2017), studies were included if they reported the number or percentage of individuals with depression assessed by semi-structured or structured diagnostic interviews based on criteria by DSMIII(-R)/IV or ICD-10, or validated self-report measures with specified clinical cut-offs. Studies were included if they reported the number or percentage of caregivers that scored above a specified cut-off for burden on a burden measure that was in line with the study's definition, and had evidence of high internal consistency, validity, and being an effective tool for assessing burden in caregivers of PwD. For instance, the Caregiver Burden Inventory (CBI; Novak and Guest 1989) and the most widely referenced burden measure, The Zarit Burden Interview (ZBI; Zarit, Reever and Bach-Peterson 1980). The cut off point for the presence of mild to severe burden on the 22 item ZBI is $>21$. Studies not reporting depression or burden prevalence data were excluded.

Initially, articles published in any year were included. However, during the screening of full text articles the authors decided that only studies published from the year 2000 
onwards were eligible for inclusion. This decision was made because a number of factors have changed substantially from prior to the year 2000 to the present day which could have impacted upon the accuracy of the current prevalence estimates of depression and burden. For example, in the 1980 's, older adult services in the United Kingdom (UK) rarely diagnosed dementia, it was common for PwD to be hospitalised, and there was a lack of psychologically informed care (Brooker 2017). In contrast, from around the 1990's there has been an increase in the formal diagnosis of dementia and a shift towards community based care, with most PwD today living in the community and receiving care from a relative or friend (Schulz and Martire 2004). The evidence base for and provision of psychosocial and psychological interventions (e.g. Cognitive Simulation Therapy; Spector et al. 2003) has also grown. Other factors taken into account included life-style changes and technological advances, the increase in the prevalence of depression in the general population (WHO 2017), and the reduction in stigma towards depression in the last 20 years (Taylor Nelson Sofres British Market Research Bureau Limited 2014) - potentially increasing the likelihood of caregivers disclosing depressive symptoms.

\section{Information sources}

A comprehensive search of the literature was conducted. The databases of PsycARTICLES, PsycINFO, MEDLINE Complete, SCOPUS and Web of Science were searched to identify relevant published articles. Unpublished articles including dissertations and theses were sought through the ProQuest global database. Hand searches were performed on the reference lists of included studies and relevant prevalence reviews and meta-analyses obtained via The Cochrane Online Library.

\section{Search}


Depression and burden in caregivers of people with dementia

The first author performed the search using the keywords and search strategies

outlined in Table 1. All databases were searched from their inception to $31^{\text {st }}$ October 2017 and no limits were applied to language.

$<$ insert table 1 here $>$

\section{Study selection}

The results of the searches were merged using EndNote software (version X8.0) and duplicate articles removed. Eligibility assessment was conducted in a non-blinded manner. The first author performed the initial screening of the titles and abstracts, whereby clearly irrelevant articles were excluded. Full text articles were screened by both authors independently using a structured checklist created by the first author (Appendix A). The kappa coefficient was 0.68 indicating substantial agreement (Cohen 1960). Disagreements between reviewers were resolved through discussions. When data from studies overlapped, the report with the largest sample size or data set was included.

\section{Data collection process}

The first author developed an electronic database which was pilot tested on a randomly-selected study by both authors collaboratively and refined accordingly. In order to reduce errors and minimise bias, both authors independently extracted the data from 11 of the included studies (10\%) and results were compared, with no significant discrepancies identified. Data extraction was completed on the remaining studies by the first author independently and the data transferred to the Comprehensive Meta-Analysis software (CMA version 3; Borenstein et al. 2005).

\section{Data items}


Information was extracted from each study based on (1) characteristics of the study (including year of publication, country, design, recruitment process, sample size and instruments used to assess depression and/or burden); (2) characteristics of the caregivers (including the definition given for a caregiver, mean age, percentage female, race, nationalities, average length of time spent caregiving in months, percentage employed, percentage married, mean years of education and types and percentages of relationships held with the care-recipients); (3) characteristics of the care-recipients (including procedure used to diagnose dementia, percentages of the types of dementia diagnoses and severity of dementia - primarily measured by a mean Mini Mental State Examination (MMSE) score); (4) depression and burden outcome data (including the number or percentage of participants within the sample that were diagnosed with depression or scored above the specified clinical cut-off, and the number or percentage of females and males, and spouses and non-spouses that were diagnosed with depression or scored above the specified cut-offs). Information was not inputted if it was missing or unclear and not made available by study authors.

\section{Risk of bias in individual studies}

The bias risk of each study was investigated using a 13-item list (Table 2) adapted from existing criteria lists (Krebber et al. 2014; Luppa et al. 2012). Quality rating scales for RCT's tend to generate an overall score of study quality or separate quality scores in key domains. The assessment tool used in this review measured the level of risk that each study posed to the reliability of the specific outcomes of the current review. Adaptations were to the list were therefore made with regards to the population being studied and focused on: (i) the description of the caregivers including information about the care-recipients' diagnosis and (ii) the representatives of this population. Items for the description of the caregivers included sociodemographic characteristics (age and gender, and at least one of the following four: marital status, education, employment or socioeconomic status), inclusion and exclusion 
criteria, dementia diagnostic procedure, dementia diagnoses and severity, time spent as a caregiver, inclusion and exclusion criteria and information about (a history) of psychiatric problems of the caregivers. Items of the representativeness of the study population included sample size $>100$, description of participation or response rate and this being at least 75 per cent, reasons for nonresponse/nonparticipation presented or a statistical comparison of the characteristics of responders and non-responders, description of the recruitment process and use of a consecutive sampling method. A risk item was given a positive score if the study provided adequate information. If the information was incomplete or unclear, a negative score was given. If a study referred to another publication describing relevant information about the first study (e.g. recruitment process), the additional publication was obtained to score the item of concern. For each study, a total bias score was calculated by counting the number of criteria scored positively; therefore the highest total score available was 13 . A study was considered of low bias risk if the score was at least 75 per cent of the total, of medium bias risk if it was between 50-75 per cent of the total and high risk if below 50 per cent of the total.

$<$ insert table 2 here $>$

The risk assessment tool was pilot tested on a randomly selected study by both authors collaboratively and refined accordingly. Subsequently, the authors independently rated eleven randomly-selected studies and compared the results. There were a few discrepancies between the ratings. If a risk item was rated positively by one author but not the other, a discussion was held and often the conservative value was chosen. The remaining studies were assessed by the first author independently.

\section{Summary measures}

Meta-analyses were conducted by computing the event rate of depression and burden using CMA (Borenstein et al. 2005). 
Depression and burden in caregivers of people with dementia

Synthesis of results

Effect sizes (event rates), their 95 per cent confidence intervals (CIs) and associated $z$ and $p$ values were computed using the number of caregivers who scored above the specified cut-offs for depression or burden and sample size. As considerable heterogeneity of event rates was expected, the pooled prevalence estimate and its 95 per cent CI were calculated using a random-effects model. To assess for heterogeneity among studies, the chi squared statistic (Q; Higgins and Thompson 2002) and I squared statistic ( $\mathrm{I}^{2}$; Higgins et al. 2003) were computed. $\mathrm{I}^{2}$ provides a percentage of the total observed variability in effect estimates due to heterogeneity rather than chance and is not affected by low statistical power. An $\mathrm{I}^{2}$ of 25 per cent is considered low, 50 per cent moderate and 75 per cent high.

\section{Risk of bias across studies}

Publication bias was assessed by constructing funnel plots, and conducting the trim and fill method (Duval and Tweedie 2000a) and Rosenthal's Fail Safe N (Rosenthal 1979). The trim and fill method estimates how many studies could be missing from each metaanalysis, corrects the funnel plot symmetry, and calculates adjusted effect size estimates. Rosenthal's Fail Safe N determines how many studies with a null result would be needed to nullify the pooled prevalence estimate. If only a few studies (e.g. five or ten) are required to cause the pooled prevalence estimate to become non-significant caution is held over the robustness of the results (Borenstein et al. 2009).

\section{Additional analyses}

A sensitivity analysis was conducted to determine whether the burden pooled prevalence estimate would have differed substantially if a study that measured 'persisting' burden (Epstein-Lubow et al. 2008) was omitted. As samples enrolled in RCTs could differ 
Depression and burden in caregivers of people with dementia

from samples who are not, a random-effects sub-group analysis was performed to determine whether prevalence estimates differed according to whether studies used a cross-sectional sample or one taken from an RCT at baseline.

Odds ratio effect sizes, their 95 per cent CI and associated $z$ and $p$ values were computed on the proportion of female caregivers compared to male caregivers that were classed as depression, and the proportion of spouses compared to non-spouses that were classed as depressed. Two meta-analyses using random effects models were conducted to ascertain the overall odds ratio estimates and their 95 per cent confidence intervals.

A random-effects meta-regression investigated the relationship between study quality and the prevalence estimates of depression and burden. A random-effects sub-group analysis was also conducted to determine whether depression prevalence estimates differed according to the type of measure used to assess depression and the continent the study was conducted in.

\section{Results}

Study selection

The database searches produced 8568 articles and hand searching 35 articles, resulting in a total of 8603 studies (Fig. 2). After the removal of 1905 duplicates, 6698 titles and abstracts were reviewed, with 6584 articles deemed clearly irrelevant and excluded. The full texts of the remaining 114 articles were screened, with 71 not fulfilling criteria and 43 studies included in the meta-analysis.

One study used a higher cut off for the burden measure compared with other included studies that used the same measure, as it assessed 'persisting burden' rather than the presence 
of burden (Epstein-Lubow et al. 2008). The authors included the study and assessed its potential impact via additional analyses.

$<$ insert fig 2 here $>$

\section{Study characteristics}

The key characteristics of the 43 included studies are provided in Table 3 . The total number of participants included in the meta-analysis was 16 911. Most of the studies were conducted in Europe (19), followed by North America (16), Asia (3), Australia (3) and South America (2). The majority of studies used cross-sectional designs (28), with the remaining studies using baseline RCT data (8), adopting a longitudinal prospective cohort design (4), and using baseline data from longitudinal prospective cohort studies (3). The recruitment procedures varied greatly across studies. Sixteen recruited from multiple different platforms. For example, Cheng, Lam and Kwok (2013) recruited caregivers from memory clinics, outpatient clinics, day hospitals, day care centres and social services. Seventeen recruited from one database or service, and 10 recruited from two or more of the same types of service, such as memory clinics (e.g. Brodaty et al. 2014).

Of the 40 studies that reported the proportionality of genders, all were predominantly female. Thirty-three studies reported the mean age of the sample (ranging from 51.8 to 83.5 years old). Of the 40 studies that reported the percentages of relationships between the caregivers and care-recipients, 20 had a majority of spouses and 20 a majority of non-spouses (typically adult children). Twenty-four studies reported the tools used to diagnose dementia or a form of dementia in all care-recipients; seven used the National Institute of Neurological and Communicative Disorders and Stroke and the Alzheimer's Disease and Related Disorders Association (NINCDS-ADRDA; McKhann et al. 1984) alone or in conjunction with other diagnostic tools or procedures. Twenty one studies reported the percentages of the care- 
Depression and burden in caregivers of people with dementia

recipients' dementia diagnoses. Ten studies were 100 per cent Alzheimer's Disease (AD), five were

$<$ insert table 3 here $>$

primarily AD followed by Vascular Dementia (VD) then other dementias, one was primarily $\mathrm{AD}$ followed by other dementias then $\mathrm{VD}$, one was 75 per cent $\mathrm{AD}$ and 25 per cent Lewy Body Dementia (LBD), one was a majority of Frontotemporal Dementia (FTD) followed by AD then other dementias, and one was 100 per cent FTD.

Structured diagnostic interviews were used in two of the 38 studies that reported the prevalence of depression; leaving 36 studies that used self-report depression measures (Table 3D). The 20-item CES D (Radloff 1977) with cut-off $\geq 16$ was used the most times (11) to measure depression. Of the nine studies that reported the prevalence of burden, eight used a version of the 22-item Zarit Burden Interview (ZBI; Zarit, Reever and Bach-Peterson 1980). Risk of bias within studies

The mean bias score was seven $(\mathrm{SD}=1.65)$, and scores ranged from four (highest risk bias) to 11 (lowest risk) (Fig. 3a). Of the 43 studies assessed, 18 had a high risk, 22 had a medium risk and three a low risk. As can be seen in Fig. 3b, over 80 per cent of the studies reported the percentages of the types of relationships between caregivers and care-recipients, and inclusion and exclusion criteria. More than half had a sample size $\geq 100$ and reported sufficient socio-demographic information, the dementia diagnostic procedure, percentages of dementia diagnoses, dementia severity, and provided an adequate description of the recruitment method. The most underreported risk items were '(history of) psychiatric problems' (14\%) and 'participation and response rates are described and are more than 75 per cent (27\%). See Figures $3 \mathrm{a}$ and $3 \mathrm{~b}$ for a full description of the risk bias assessment results.

$<$ insert fig $3 \mathrm{a}$ and fig $3 \mathrm{~b}$ here $>$ 
Depression and burden in caregivers of people with dementia

\section{Results of individual studies}

Fig. 4 and Fig. 5 show forest plots of prevalence estimates for burden and depression, including their $\mathrm{CI}$ and associated $z$ and $p$ values.

Synthesis of results

Prevalence of depression

Thirty-eight studies included prevalence estimates of depression. These ranged from three per cent to 57 per cent; although it must be noted that the study with a three per cent prevalence estimate (Lowery et al. 2000) had the highest standard error and could be considered an outlier (Copas and Shi 2000). Overall, prevalence estimates of depression yielded a pooled prevalence of 33.6 per cent (CI $29.9 \%$ to $37.5 \% \mathrm{p}<.001$ ). However, the heterogeneity of the prevalence estimates was significantly high $\left(I^{2}=93.96 \%, Q=612.31, p\right.$ $<.001)$.

$<$ insert fig 4 here $>$

Prevalence of burden

Nine studies reported prevalence estimates of burden. These estimates ranged from 35.8 per cent to 88.5 per cent, with a pooled prevalence of 62.5 per cent (CI $51.2 \%$ to $72 \%$, p $=.031)$. However, heterogeneity of the prevalence estimates was significantly high $\left(\mathrm{I}^{2}=\right.$ $94.90 \%, \mathrm{Q}=157, \mathrm{p}<.001)$

$<$ insert fig 5 here $>$

Risk of bias across studies

Studies on depression

The depression pooled prevalence estimate corresponded to a $\mathrm{z}$ value of -28.77 $(\mathrm{p}<.00001)$ indicating that 8149 studies with a null effect size would be needed before the combined two-tailed p-value would exceed 0.05 , suggesting that the observed effect estimates may be extremely robust. The trim and fill method indicated four potentially 
missing studies that would need to fall on the left side of the pooled prevalence estimate to make the plot symmetrical (Fig 6). Assuming a random-effects model, the new pooled prevalence estimate reduced to 31.24 per cent (CI $27.70 \%$ to $35.01 \%$ ).

$<$ insert fig 6 here $>$

\section{Studies on burden}

The burden pooled prevalence estimate corresponded to a $\mathrm{z}$ value of $5.914(\mathrm{p}<.00001)$ indicating that 73 studies with a null effect would be needed before the combined two-tailed p-value would exceed 0.05 , suggesting that the observed prevalence estimates may be robust. The trim and fill method indicated three potentially missing studies that would need to fall on the left side of the pooled prevalence estimate to make the plot symmetrical (Fig 7). Assuming a random-effects model, the new pooled prevalence estimate reduced to 49.26 per cent (CI $37.15 \%$ to $61.46 \%)$.

$<$ insert fig 7 here $>$

Additional analyses

Sensitivity analysis

Following the omission of Epstein-Lubow et al. (2008) the prevalence of burden increased by a minimal percentage (1.4\%). The analysis found no deviations from the main analysis in terms of heterogeneity or significance of results.

\section{Subgroup analysis}

Random-effects sub group analysis comparing RCT data to non-RCT data was not appropriate for burden outcomes, given that only one of the nine studies used baseline RCT data (Epstein-Lubow et al. 2008). The depression pooled prevalence estimate of studies that used baseline RCT data did not significantly differ to that of studies where samples were obtained via cross-sectional or longitudinal prospective cohort designs $(p=.734)$. The second random-effects sub-group analysis included thirty-two studies and revealed that depression 
Depression and burden in caregivers of people with dementia

prevalence estimates differed according to the type of measure used $(p=.003)$; two studies that used diagnostic criteria reported the lowest prevalence rate $\left(8.9 \%\right.$, CI $3.4 \%$ to $21.4 \%, \mathrm{I}^{2}=$ $88.01 \%$ ), although one of these studies may be considered an outlier, followed by studies that used a form of the Hospital Anxiety and Depression Scale (HADS; 26\%, CI 15.6\% to 40.1\%, $\mathrm{I}^{2}=95.89 \%$ ). Five studies that used a form of the Beck Depression Inventory (BDI) reported the highest prevalence estimate $\left(49.2 \%\right.$, CI $34.3 \%$ to $\left.64.2 \%, \mathrm{I}^{2}=59.66 \%\right)$. As there were no studies conducted in Africa and only one study based in South America reporting depression prevalence data, the random-effects sub-group analysis for continent compared the pooled prevalence estimates of Asia, Europe, Australia and North America. There was a significant difference between the depression pooled prevalence estimates of the continents entered into the analysis $(\mathrm{p}<.0007)$, with Asia reporting the lowest estimate of 26.8 per cent (CI $17.2 \%$ to 39.2\%), followed by North America 29.1 per cent (CI 24.3\% to 34.6\%), Europe 36.8 per cent (CI $31.1 \%$ to $42.8 \%$ ) and Australia yielding the highest estimate of 58.1 per cent (CI $40.0 \%$ to $74.3 \%)$.

Meta-regression results

Study quality was not a significant moderator of depression prevalence estimates $(0.0254, \mathrm{CI}-0.0816$ to $0.1324, \mathrm{p}=.641)$ or burden prevalence estimates $(-0.18, \mathrm{CI} 0.144$ to $0.461, \mathrm{p}=.215)$

\section{Odds-ratio meta-analyses}

The first meta-analysis included eight studies (Fig 8) and revealed that the odds of a female caregiver having depression was one point four five times higher than a male caregiver (CI 1.125 to $1.874, \mathrm{p}=.004)$. There was no significant heterogeneity of the odds ratio estimates. The pooled odds ratio estimate corresponded to a $\mathrm{z}$ value of three point eight five four $(\mathrm{p}=.001)$ indicating that 23 studies with a null effect would be needed to reduce the p-value to below the significance level, suggesting that the odd ratios may not be robust. 
However, the trim and fill method indicated no missing studies from the analysis. The second meta-analysis included seven studies and the odds of a spouse compared to a non-spouse having depression was found to be one point one five, however this was not significant (CI 0.737 to $\left.1.779, \mathrm{I}^{2}=84.42, \mathrm{p}=.547\right)$. The trim and fill method suggested there were no missing studies from this analysis.

\section{Discussion}

Forty-three studies set across five of the seven continents, predominantly comprising of cross-sectional designs, were examined with a combined total of 16911 participants. To our knowledge, this was the first meta-analysis to quantify the prevalence of perceived burden among informal caregivers of PwD. Overall the trim-and-fill adjusted prevalence estimate of burden was 49.26 per cent. In other words, approximately half of all the informal caregivers of PwD perceive their caregiving role to be mildly to severely burdening. This result was indicated to be robust in the context of publication bias. There may be numerous reasons for why the remaining half of the population perceives their role to have little or no burden, including that these caregivers perceive more positive benefits from the acquisition of the role. For example, if a caregiver perceives that their family has become closer together, this could impact upon their response to questions regarding the social impact of the role - a construct of burden. Importantly, the finding highlights a great need within this population for interventions effective at reducing burden. Such interventions could increase the wellbeing of caregivers during their role, which could prolong the transition of carerecipients to care homes, and prevent post-death psychiatric morbidity (Gaugler et al. 2005).

The trim-and-fill adjusted prevalence estimate of depression was 31.24 per cent, suggesting that almost a third of all caregivers of $\mathrm{PwD}$ are experiencing depression. Rosenthal's fail safe $N$ indicated that this finding was extremely robust, with over 8000 extra studies with a null effect required to nullify the result. The depression prevalence estimate is 
substantially higher than that of the prevalence of depression among adult primary care patients, assessed via structured diagnostic interviews (Mitchell, Vaze and Rao 2009) and the prevalence of depression in older adult populations, assessed via self-report measures (Li et al. 2014; Luppa et al. 2012). Given that depression has been found to be a risk factor for suicidal ideation among family caregivers of $\mathrm{PwD}$, the high prevalence of depression supports the finding of higher prevalence rates of suicidal ideation in this population compared to the general population (O’Dwyer et al 2013; O'Dwyer et al. 2016). Overall, the finding demonstrates that more informal caregivers of PwD are in need of interventions to reduce depressive symptoms than the adult/older adult general population.

Interestingly the depression prevalence estimate is higher than that found in the study of Cuijpers (2005). This could be attributed to the fact that all of the studies within Cuijpers (2005) were conducted at least 12 years ago and therefore its estimate may not reflect the current prevalence in today's population. The difference could also be due to the fact that all studies in Cuijpers (2005) were based in either the UK or the United States, unlike the current review which included depression prevalence estimates from studies conducted in numerous countries across Europe, multiple states in North America, and several places in Asia and Australia. In addition to this, the current review included almost four times as many studies and so may have provided a more accurate prevalence estimate. Finally, the review of Cuijpers (2005) only included studies that assessed depression via semi-structured or structured diagnostic interviews, whereas the current meta-analysis also included studies that assessed depression via self-report measures. It has been reported that, compared with selfreport measures, interview methods commonly underestimate the prevalence of psychiatric disorders (Mitchell et al. 2011). In line with this and the findings of other meta-analytic reviews (e.g. Krebber et al. 2014), the current review discovered that the depression prevalence estimates differed according to the instrument used to assess depression, with 
interviews based on diagnostic criteria yielding the lowest pooled prevalence estimate. This could also explain why the overall depression prevalence estimate was similar to that found in Sallim et al. (2015), where studies assessing depression via self-report measures were included.

The review also found that female caregivers are 1.45 times more likely to experience depression than male caregivers. Although, this finding may not be robust in the context of publication bias, and further observational studies comparing the prevalence of depression between male and female caregivers of PwD are warranted. No significant difference in terms of depression prevalence was observed between spousal and non-spousal caregivers; indicating that caregivers who are adult children, friends or other relatives of the carerecipient may be just as much at risk of developing depression as caregivers who are spouses of the care-recipient. This outcome did not support the finding of Sallim et al. (2015), where spousal caregivers of patients with AD were significantly more likely than non-spousal caregivers of patients with $\mathrm{AD}$ to experience depression. It is not thought that this is attributed to the fact that the current review included caregivers of people with all forms of dementia, but because it included over twice as many studies - three of which reported a higher prevalence of depression in non-spousal compared to spousal caregivers. Some research has indicated that it may not be the type of relationship that poses a risk for depression but the caregiver's perception of the quality of the relationship. For example, Kramer (1993), Williamson and Schulz (1993) and Fauth et al. (2012) found closer relationships prior to the onset of dementia predicted lower levels of depressive symptoms. Furthermore, Morris, Morris and Britton (1998) found caregivers with lower levels of intimacy prior to and following the onset of dementia had higher levels of depressive symptoms.

\section{Limitations}


Although study quality was not found to be a significant moderator of the burden or depression prevalence estimates, 18 studies were rated as having a high risk of bias and only three studies rated as having a low risk of bias. The majority of studies failed to report any details of the history of psychiatric problems for the informal caregivers. Most did not report details of the participation and response rates or when these were reported they were less than 75 per cent, and most studies did not compare those that did respond/participate to those that did not (either qualitatively or quantitatively). This could mean that within these studies a large proportion of caregivers did not respond/participate. If this were true, this could have affected the accuracy of the burden prevalence estimate particularly given that one of the reasons some informal caregivers of PwD do not engage with services is due to a high level of burden (Brodaty, Thompson and Fine, 2005).

Another limitation of the review, and a major limitation of this field of research, is that most studies used convenience based samples rather than population based samples. Pruchno et al. (2008) discovered that caregivers recruited via convenience sampling methods reported higher levels of burden and increased depressive symptomatology relative to those identified using a population based sampling method. This is therefore a serious methodological concern in that convenience samples are likely to exaggerate the prevalence of depression and burden considerably and therefore the findings may not be reliably generalizable (Pruchno et al. 2008). Future research should endeavour to recruit a consecutive sample of the population.

Another limitation is the findings of significantly high heterogeneity of depression and burden prevalence estimates. This suggests that these are not similar across studies and conclusions drawn are limited by this fact. Interestingly, the purpose of recruitment did not appear to impact the prevalence estimates as the pooled prevalence of studies that used baseline RCT data did not significantly differ to that obtained for studies using cross- 
sectional designs and longitudinal prospective cohort designs. The heterogeneity among depression prevalence estimates was however partially explained by the type of instruments used to measure depression, with studies using diagnostic criteria yielding the lowest pooled prevalence estimate. In terms of self-report measures, studies that used a form of the HADS yielded the lowest pooled prevalence estimate and studies using a form of the BDI had the highest pooled prevalence estimate. These findings reflect those of a recent meta-analysis of the prevalence of depression among medical outpatients (Wang et al. 2017). The self-report measures are designed to assess clinically significant depressive symptoms but they are not tools for diagnosing different types of mood disorders; for example, the HADS does not include all of the diagnostic criteria for depression based on DSM (Laidlaw 2015). It is therefore perhaps unsurprising that the two studies that used diagnostic criteria reported the lowest prevalence rate. Moreover, the HADS was designed to detect depression and anxiety in people with medical conditions, and thus it is useful for older people with chronic physical illnesses. Although the BDI is a well-established measure, it can be criticised for having somatic scale items as this may inflate scores when used with older people (Laidlaw 2015). Considering that many informal caregivers of PwD are older people, this may account for the significantly large difference observed between the pooled prevalence estimates of studies that used the HADS and the BDI. It is also acknowledged that different cut-offs may have affected the diagnostic sensitivity and specificity.

The study also revealed that prevalence estimates differed by continent. Asia appeared to have the lowest prevalence of depression, followed by North America, Europe and Australia, respectively. Unfortunately, the review could not include South America within the sub-group analysis as only one study conducted in this region reported the prevalence of depression, and overall no included study was conducted in Africa. This leaves a question as 
Depression and burden in caregivers of people with dementia

to whether the prevalence of depression among informal caregivers of PwD differs greatly in these continents.

\section{Conclusion}

In summary, this review revealed that almost one third of informal caregivers of PwD experience depression and approximately one half appraise their caregiving role to be burdensome. Unfortunately, significant heterogeneity of depression and burden prevalence estimates was observed. As reported in other reviews, different screening instruments were found to produce different estimates of depression. The heterogeneity of depression prevalence estimates was also partially explained by the continent the studies were conducted in, with Asia reporting the lowest prevalence and Australia the highest. Female caregivers were found to be more at risk of experiencing depression than male caregivers. However, further observational studies investigating this finding are warranted. No significant difference in terms of depression prevalence was observed between spousal and non-spousal caregivers. Based on previous literature, it is suggested that a caregiver's vulnerability to developing depression may be more related to the quality of the relationship with the carerecipient as opposed to the relationship type. The review demonstrates that within this population there is a great need for the provision of interventions that are effective at reducing burden and depressive symptoms. Given that these difficulties can negatively impact upon a caregiver's health, ability to perform their role (Gallagher et al. 1989; Cucciare et al. 2010), and increase the likelihood of the care-recipient being transitioned to a nursing home placement (Gaugler et al. 2005), economically, it would appear vital for dementia services to promptly establish or tailor existing interventions to treat these difficulties. 
Depression and burden in caregivers of people with dementia

Role of funding sources: This work was supported by the Clinical Psychology Course at the University of East Anglia, who provided financial support for the CMA software. The authors work within the institution, however no other UEA personal were involved in the study design, collection, analysis or interpretation of the data, writing the manuscript, or the decision to submit the paper for publication.

Contributors: The first author designed the study, collected the data, analysed the title, abstracts and all full texts, conducted statistical analyses, interpreted the data and wrote the manuscript. The second author contributed to analysing full text articles and assessing eligibility, extracting the data and analysing the quality of selected studies, and editing and proof reading the manuscript. Both authors have approved the final manuscript.

Conflicts of interest: All authors disclose no conflicts of interest. 
Depression and burden in caregivers of people with dementia

\section{References}

Adams B, Aranda MP, Kemp B. and Takagi K (2002) Ethnic and gender differences in distress among Anglo American, African American, Japanese American, and Mexican American spousal caregivers of persons with dementia. Journal of Clinical Geropsychology, 8, 279-301.

Alzheimer's Disease International (2013) World Alzheimer's Report 2013: An analysis of long-term care for dementia. Retrieved from, https://www.alz.co.uk/research/WorldAlzheimerReport2013.pdf

Alzhiemer's Disease International (2015) World Alzheimer's Report 2015. The global impact of dementia: The Global Impact of Dementia: An analysis of prevalence, incidence, cost and trends. Retrieved from, https://www.alz.co.uk/research/worldreport-2015

Alzheimer's Research UK (2015) Women and dementia: a marginalised majority. Retrieved from, https://www.alzheimersresearchuk.org/wp-content/uploads/2015/03/Women -and-Dementia-A-Marginalised-Majority1.pdf

Alzheimer's Society (2014) Care for today and cure for tomorrow: Alzhimer's Society strategy for funding research 2014-2017. Retrieved from, https://www.alzheimers.org.uk/download/downloads/id/2254/care for today and cure for tomorrow.pdf

American Psychiatric Association (1980) Diagnostic and statistical manual of mental disorders ( $3^{\text {rd }}$ ed.). Washington, DC: American Psychiatric Publishing.

American Psychiatric Association (1987) Diagnostic and statistical manual of mental disorders ( $3^{\text {rd }}$ ed. Text Revision.). Washington, DC: American Psychiatric Publishing. 
Depression and burden in caregivers of people with dementia

American Psychiatric Association (1994) Diagnostic and statistical manual of mental disorders ( $4^{\text {th }}$ ed.). Washington, DC: American Psychiatric Publishing.

American Psychiatric Association (2000) Diagnostic and statistical manual of mental disorders ( $4^{\text {th }}$ ed. Text revision.). Washington, DC: American Psychiatric Publishing American Psychiatric Association (2013) Diagnostic and statistical manual of mental disorders $\left(5^{\text {th }}\right.$ ed.). Washington, DC: American Psychiatric Publishing.

Andresen EM, Malmgren JA, Carter WB and Patrick DL (1994) Screening for depression in well older adults: Evaluation of a short form of the CES-D (Center for Epidemiologic Studies Depression Scale). American Journal of Preventive Medicine, 10, 77-84.

Arango Lasprilla JC, Moreno A, Rogers H and Francis K (2009) The effect of dementia patient's physical, cognitive, and emotional/behavioral problems on caregiver wellbeing: findings from a Spanish-speaking sample from Colombia, South America. American Journal of Alzheimer's Disease \& Other Dementias ${ }^{\circledR}, 24,384-$ 395

Beck AT and Beck RW (1972) Screening depressed patients in family practice: a rapid technique. Postgraduate Medicine, 52, 81-85.

Beck AT, Steer,RA, Ball R and Ranieri W (1996) Comparison of Beck Depression Inventories - IA and -II in psychiatric outpatients. Journal of Personality Assessment, 67, 588-597.

Beck AT, Ward CH, Mendelson M, Mock J and Erbaugh J (1961) An inventory for measuring depression. Archives of General Psychiatry, 4, 561-571.

Bednarek A, Mojs E, Krawczyk-Wasielewska A, Głodowska K, Samborski W, Lisiński P, Kopczyński P, Gregersen R and Millán-Calenti JC (2016) Correlation between 
Depression and burden in caregivers of people with dementia

depression and burden observed in informal caregivers of people suffering from dementia with time spent on caregiving and dementia severity. Eur Rev Med Pharmacological Science, 20, 59-63.

Bejjani C, Snow AL, Judge KS, Bass DM, Morgan RO, Wilson N, Walder A, Looman WJ, McCarthy C and Kunik ME (2015) Characteristics of depressed caregivers of veterans with dementia. American Journal of Alzheimer's Disease \& Other Dementias, 30, $672-678$.

Berger G, Bernhardt T, Weimer E, Peters J, Kratzsch T and Frolich L (2005) Longitudinal study on the relationship between symptomatology of dementia and levels of subjective burden and depression among family caregivers in memory clinic patients. Journal of Geriatric Psychiatry and Neurology, 18, 119-128.

Borenstein M, Hedges L, Higgins, J and Rothstein H (2005) Comprehensive metaanalysis (version 2). Englewood, NJ: Biostat.

Borenstein M, Hedges LV, Higgins J and Rothstein HR (2009) Introduction to meta analysis. Chichester, West Sussex: John Wiley \& Sons, Ltd.

Borsje P, Hems MA, Lucassen PL, Bor H, Koopmans RT and Pot AM (2016) Psychological distress in informal caregivers of patients with dementia in primary care: course and determinants. Family Practice, 33, 374-381.

Breinbauer H, Vásquez H, Mayanz S, Guerra C and Millán T (2009) Validación en Chile de la Escala de Sobrecarga del Cuidador de Zarit en sus versiones original y abreviada. Revista Médica de Chile, 137, 657-665.

Brodaty H and Donkin M (2009) Family caregivers of people with dementia. Dialogues in Clinical Neuroscience, 11, 217. 
Depression and burden in caregivers of people with dementia

Brodaty H, Thomson C, Thompson C and Fine M (2005) Why caregivers of people with dementia and memory loss don't use services. International Journal of Geriatric Psychiatry, 20, 537-546.

Brodaty H, Woodward M, Boundy K, Ames D, Balshaw R and PRIME Study Group (2014) Prevalence and predictors of burden in caregivers of people with dementia. The American Journal of Geriatric Psychiatry, 22, 756-765.

Brooker D (2017) How has the field of dementia care changed in the past 30 years? Retrieved from, http://www.jkp.com/jkpblog/2017/05/dementia-field-changes-30years.

Caspar S and O'Rourke N (2009) The composition and structure of depressive symptomatology among young and older caregivers of persons with dementia. Ageing International, 34, 33-41.

Chan YF, Leung DY, Fong DY, Leung CM and Lee AM (2010) Psychometric evaluation of the Hospital Anxiety and Depression Scale in a large community sample of adolescents in Hong Kong. Qual Life Res, 19, 865-873.

Collins RN, Gilligan LJ and Poz R (2018) The Evaluation of a Compassion-Focused Therapy Group for Couples Experiencing a Dementia Diagnosis. Clinical Gerontologist, 41, 474-486.

Conde C and Useros E (1975) Adaptación castellana de la escala de evaluación conductual para la depresión de Beck. Revista de Psiquiatría y Psicología Médica de Europa y América Latinas, 12, 217-236.

Cheng ST, Lam LC and Kwok T (2013) Neuropsychiatric symptom clusters of Alzheimer disease in Hong Kong Chinese: correlates with caregiver burden and depression. The American Journal of Geriatric Psychiatry, 21, 1029-1037. 
Depression and burden in caregivers of people with dementia

Chiao CY, Wu HS and Hsiao CY (2015) Caregiver burden for informal caregivers of patients with dementia: a systematic review. International Nursing Review, 62, 340 -350 .

Cohen J (1960) A coefficient of agreement for nominal scales. Educational and Psychological Measurement, 20, 37-46.

Cohen CA, Colantonio A and Vernich L (2002) Positive aspects of caregiving: rounding out the caregiver experience. International Journal of Geriatric Psychiatry, 17, 184-188.

Contador I, Fernández-Calvo B, Palenzuela DL, Miguéis S and Ramos F (2012) Prediction of burden in family caregivers of patients with dementia: A perspective of optimism based on generalized expectancies of control. Aging \& Mental Health, 16, $675-682$.

Copas J and Shi JQ (2000) Meta-analysis, funnel plots and sensitivity analysis. Biostatistics, 1, 247-262.

Covinsky KE, Newcomer R, Fox P, Wood J, Sands L, Dane K and Yaffe K (2003) Patient and caregiver characteristics associated with depression in caregivers of patients with dementia. Journal of General Internal Medicine, 18, 1006-1014.

Cucciare MA, Gray H, Azar A, Jimenez D and Gallagher-Thompson D (2010) Exploring the relationship between physical health, depressive symptoms, and depression diagnoses in Hispanic dementia caregivers. Aging \& Mental Health, 14, 274-282.

Cuijpers P (2005) Depressive disorders in caregivers of dementia patients: a systematic review. Aging \& Mental Health, 9, 325-330.

Duval S and Tweedie R (2000a) Trim and fill: a simple funnel-plot-based method of testing and adjusting for publication bias in meta-analysis. Biometrics, 56, 455463. 
Depression and burden in caregivers of people with dementia

Dilworth-Anderson P and Anderson N (1994) Dementia caregiving in Blacks: A contextual approach to research. In E Light, G Niederehe and B Lebowitz (Eds.) Stress effects on family caregivers of Alzheimer's patients (pp. 385-409). New York: Springer.

Epstein-Lubow G, Davis JD, Miller IW and Tremont G (2008) Persisting burden predicts depressive symptoms in dementia caregivers. Journal of Geriatric Psychiatry and Neurology, 21, 198-203.

Etters L, Goodall D and Harrison BE (2008) Caregiver burden among dementia patient caregivers: a review of the literature. Journal of the American Association of Nurse Practitioners, 20, 423-428.

Fauth E, Hess K, Piercy K, Norton M, Corcoran C, Rabins P, Lyketsos C and Tschanz J (2012) Caregivers' relationship closeness with the person with dementia predicts both positive and negative outcomes for caregivers' physical health and psychological well-being. Aging \& Mental Health, 16, 699-711.

First MB, Spitzer RL, Gibbon M and Williams JBW (2008) Structured clinical interview for DSM-IV axis I disorders-clinician version (SCID-I). In AJ Rush, MB First and D Blacker (Eds.) Handbook of psychiatric measures (2nd ed., pp. 40-43). Washington, DC: American Psychiatric Publishing.

Folstein MF, Folstein SE and McHugh PR (1975) "Mini-mental state”: a practical method for grading the cognitive state of patients for the clinician. Journal of Psychiatric Research, 12, 189-198.

Gallagher D, Ni Mhaolain A, Crosby L, Ryan D, Lacey L, Coen RF, Walsh C, Coakley D, Walsh JB, Cunningham C and Lawlor BA (2011) Self-efficacy for managing dementia may protect against burden and depression in Alzheimer's caregivers. Aging \& Mental Health, 15, 663-670 
Depression and burden in caregivers of people with dementia

Gallagher D, Rose J, Rivera P, Lovett S and Thompson LW (1989) Prevalence of depression in family caregivers. The Gerontologist, 29, 449-456.

García-Alberca JM, Cruz B, Lara JP, Garrido V, Gris E, Lara A and Castilla C (2012)

Disengagement coping partially mediates the relationship between caregiver burden and anxiety and depression in caregivers of people with Alzheimer's disease. Results from the MÁLAGA-AD study. Journal of Affective Disorders, 136, 848-856.

Gaugler JE, Kane RL, Kane RA and Newcomer R (2005) Unmet care needs and key outcomes in dementia. Journal of the American Geriatrics Society, 53, 20982105.

Germain S, Adam S, Olivier C, Cash H, Ousset PJ, Andrieu S, Vellas B, Meulemans T, Reynish E and Salmon E (2009) Does cognitive impairment influence burden in caregivers of patients with Alzheimer's disease? Journal of Alzheimer's Disease, 17, 105-114.

Given CW, Given B, Azzouz F, Kozachik S and Stommel M (2001) Predictors of pain and fatigue in the year following diagnosis among elderly cancer patients. Journal of Pain Symptom Management, 21, 456-66.

Givens JL, Mezzacappa C, Heeren T, Yaffe K and Fredman L (2014) Depressive symptoms among dementia caregivers: Role of mediating factors. The American Journal of Geriatric Psychiatry, 22, 481-488.

Goldberg D, Bridges K, Duncan-Jones P and Grayson D (1988) Detecting anxiety and depression in general medical settings. British Medical Journal, 97, 897-899.

Hamilton M (1980) Rating depressive patients. Journal of Clinical Psychiatry. 41, 21-24.

Harbord R (2010) Investigating heterogeneity: sub-group analysis and meta-regression [PowerPoint slides]. Retrieved from 
Depression and burden in caregivers of people with dementia

http://methods.cochrane.org/sites/methods.cochrane.org.statistics/files/public/upl $\underline{\text { oads/ }}$

SMG_training_course_cardiff/2010_SMG_training_cardiff_day1_session4_harbord.p $\mathrm{df}$

Hasegawa N, Hashimoto M, Koyama A, Ishikawa T, Yatabe Y, Honda K, Yuuki S., Araki K and Ikeda M (2014). Patient-related factors associated with depressive state in caregivers of patients with dementia at home. Journal of the American Medical Directors Association, 15, 371.e15-317.e18.

Hays JC, Blazer DG and Gold DT (1993) CES-D: Cutpoint or Change Score? Journal of the American Geriatrics Society, 41, 344-345.

Higgins JPT and Thompson SG (2002) Quantifying heterogeneity in a metaanalysis. Statistics in Medicine, 21, 1539-1558.

Higgins JPT, Thompson SG, Deeks JJ and Altman DG (2003) Measuring inconsistency in meta-analyses. BMJ: British Medical Journal, 327, 557.

Holland JM, Thompson LW, Tzuang M and Gallagher-Thompson D (2010)

Psychosocial factors among Chinese American women dementia caregivers and their association with salivary cortisol: Results of an exploratory study. Ageing International, 35, 109-127.

Hoppes S, Bryce H, Hellman C and Finlay E (2012) The effects of brief mindfulness training on caregivers' well-being. Activities, Adaptation \& Aging, 36, 147-166.

Hughes CP, Berg L, Danziger WL, Coben LA and Martin R (1982) A new clinical scale for the staging of dementia. The British Journal of Psychiatry, 140, 566-572. 
Jang Y, Clay OJ, Roth DL, Haley WE and Mittelman MS (2004) Neuroticism and longitudinal change in caregiver depression: Impact of a spouse-caregiver intervention program. The Gerontologist, 44, 311-317.

Joling KJ, O'Dwyer ST, Hertogh CM and Hout HP (2018) The occurrence and persistence of thoughts of suicide, self-harm and death in family caregivers of people with dementia: a longitudinal data analysis over 2 years. International Journal of Geriatric Psychiatry, 33, 263-270.

Jorm AF (2004) The Informant Questionnaire on cognitive decline in the elderly (IQCODE): a review. International Psychogeriatrics, 16, 275-293.

Kaiser S and Panegyres PK (2007) The psychosocial impact of young onset dementia on spouses. American Journal of Alzheimer's Disease \& Other Dementias ${ }^{\circledR}, 21,398$ 402.

Kemp BJ and Adams B (1995) The Older Adult Health and Mood Questionnaire: A measure of geriatric depressive disorder. Journal of Geriatric Psychiatry and Neurology. 8, 162-167.

Kramer BJ (1993) Marital history and the prior relationship as predictors of positive and negative outcomes among wife caregivers. Family Relations, 42, 367-375

Krebber AMH, Buffart LM, Kleijn G, Riepma IC, Bree R, Leemans CR, Becker A, Brug J, Straten A, Cuijpers P and Verdonck-de Leeuw IM (2014) Prevalence of depression in cancer patients: a meta-analysis of diagnostic interviews and self report instruments. Psycho-Oncology, 23, 121-130.

Kroenke K, Spitzer RL and Williams JB (2001) The PHQ9: validity of a brief depression severity measure. Journal of General Internal Medicine, 16, 606-613.

Kurz X, Scuvée-Moreau J, Vernooij-Dassen M and Dresse A (2003) Cognitive impairment, dementia and quality of life. Acta Neurologica Belgica, 103, 24-34. 
Depression and burden in caregivers of people with dementia

Laidlaw K (2015) Cognitive behaviour therapy for older people: An introduction. London: SAGE Publications.

Li D, Zhang DJ, Shao JJ, Qi XD and Tian L (2014) A meta-analysis of the prevalence of depressive symptoms in Chinese older adults. Archives of Gerontology and Geriatrics, 58, 1-9.

Liang X, Guo Q, Luo J, Li F, Ding D, Zhao Q and Hong Z (2016) Anxiety and depression symptoms among caregivers of care-recipients with subjective cognitive decline and cognitive impairment. BMC Neurology, 16, 191.

Lowery K, Mynt P, Aisbett J, Dixon T, O’Brien J and Ballard C (2000) Depression in the carers of dementia sufferers: a comparison of the carers of patients suffering from dementia with Lewy bodies and the carers of patients with Alzheimer's disease. Journal of Affective Disorders, 59, 61-65.

Lu YYF and Austrom MG (2005) Distress responses and self-care behaviors in dementia family caregivers with high and low depressed mood. Journal of the American Psychiatric Nurses Association, 11, 231-240.

Luchsinger JA, Tipiani D, Torres-Patiño G, Silver S, Eimicke JP, Ramirez M, Teresi J and Mittelman M (2015) Characteristics and mental health of hispanic dementia caregivers in New York City. American Journal of Alzheimer's Disease \& Other Dementias ${ }^{\circledR}, \mathbf{3 0}, 584-590$.

Luppa M, Sikorski C, Luck T, Ehreke L, Konnopka A, Wiese B, Weyerer S, König, HH and Riedel-Heller SG (2012) Age-and gender-specific prevalence of depression in latestlife-systematic review and meta-analysis. Journal of Affective Disorders, 136, 212 221. 
Mahoney R, Regan C, Katona C and Livingston G (2005) Anxiety and depression in family caregivers of people with Alzheimer disease: the LASER-AD study. The American Journal of Geriatric Psychiatry, 13, 795-801.

Martín M, Salvadór I, Nadal S, Miji L, Rico J, Lanz P and Taussig M (1996) Adaptación para nuestro medio de la Escala de Sobrecarga del Cuidador (Caregiver Burden Interview) de Zarit. Revista Gerontolo' gica, 6, 338-346.

Medrano M, Rosario RL, Payano AN and Capellán NR (2014) Burden, anxiety and depression in caregivers of Alzheimer patients in the Dominican Republic. Dementia \& Neuropsychologia, 8, 384-388.

McConaghy R and Caltabiano ML (2005) Caring for a person with dementia: Exploring relationships between perceived burden, depression, coping and well-being. Nursing \& Health Sciences, 7, 81-91.

McKhann G, Drachman D, Folstein M, Katzman R, Price D and Stadlan EM (1984) Clinical diagnosis of Alzheimer's disease: report of the NINCDS-ADRDA Work Group under the auspices of Department of Health and Human Services Task Force on Alzheimer's Disease. Neurology, 34, 939-44

Medrano M, Rosario RL, Payano AN and Capellán NR (2014) Burden, anxiety and depression in caregivers of Alzheimer patients in the Dominican Republic. Dementia \& Neuropsychologia, 8, 384-388.

Mitchell AJ, Chan M, Bhatti H, Halton M, Grassi L, Johansen C and Meader N (2011) Prevalence of depression, anxiety, and adjustment disorder in oncological, haematological, and palliative-care settings: a meta-analysis of 94 interview-based studies. The Lancet Oncology, 12, 160-174. 
Depression and burden in caregivers of people with dementia

Mitchell AJ, Vaze A and Rao S (2009) Clinical diagnosis of depression in primary care: a meta-analysis. The Lancet, 374, 609-619.

Moher D, Liberati A, Tetzlaff J, Altman DG and Prisma Group (2009) Preferred reporting items for systematic reviews and meta-analyses: the PRISMA statement. PLoS Medicine, 6, e1000097.

Montgomery SA and Asberg M (1979) A new depression scale designed to be sensitive to change. Br. J. Psychiatry 134, 382-389.

Morris RG, Morris LW and Britton PG (1998) Factors affecting the emotional well-being of caregivers of dementia sufferers. British Journal of Psychiatry, 153, 147-156.

Munn Z, Moola S, Lisy K and Riitano D (2014) The Joanna Briggs institute reviewer's manual 2014: The systematic review of prevalence and incidence data. South Australia: The Joanna Briggs Institute.

Novak M. and Guest C (1989) Application of a multidimensional caregiver burden inventory. The Gerontologist, 29, 798-803.

O’Brien E (2016) Alzheimer's diagnosis can mean steep costs for family caregivers. Retrieved from, http://time.com/money/4501444/alzheimers-family-caregivers -steep-costs/

O'Dwyer ST, Moyle W, Zimmer-Gembeck M and De Leo D (2013) Suicidal ideation in family carers of people with dementia: a pilot study. International Journal of Geriatric Psychiatry, 28, 1182-1188.

O'Dwyer ST, Moyle W, Zimmer-Gembeck M and De Leo D (2016) Suicidal ideation in family carers of people with dementia. Aging \& Mental Health, 20, 222-230.

Orgeta V and Lo Sterzo E (2013) Sense of coherence, burden, and affective symptoms in family carers of people with dementia. International Psychogeriatrics, 25, 973980. 
Depression and burden in caregivers of people with dementia

Ornstein K and Gaugler JE (2012) The problem with "problem behaviors": a systematic review of the association between individual patient behavioral and psychological symptoms and caregiver depression and burden within the dementia patient-caregiver dyad. International Psychogeriatrics, 24, 1536-1552.

Ory MG, Hoffman III RR, Yee JL, Tennstedt S and Schulz R (1999) Prevalence and impact of caregiving: A detailed comparison between dementia and non dementia caregivers. The Gerontologist, 39, 177-186.

Ostojić D, Vidović D, Baceković A, Brecić P and Jukić V (2014) Prevalence of anxiety and depression in caregivers of Alzheimer's dementia patients. Acta Clin Croat, 53, 17-21.

Pinquart M and Sörensen S (2003) Differences between caregivers and non caregivers in psychological health and physical health: a meta-analysis. Psychology and Aging, 18, $250-267$.

Piercy KW, Fauth EB, Norton MC, Pfister R, Corcoran CD, Rabins PV, Lyketsos C and Tschanz JT (2012) Predictors of dementia caregiver depressive symptoms in a population: The Cache County Dementia Progression Study. Journals of Gerontology Series B: Psychological Sciences and Social Sciences, 68, 921-926.

Pruchno RA, Brill JE, Shands Y, Gordon J R, Genderson MW, Rose M and Cartwright F (2008) Convenience samples and caregiving research: how generalizable are the findings? The Gerontologist, 48, 820-827.

Radloff LS (1977) The CES-D scale: A self-report depression scale for research in the general population. Applied Psychological Measurement, 1, 385-401.

Raggi A, Tasca D, Panerai S, Neri W and Ferri R (2015) The burden of distress and related coping processes in family caregivers of patients with Alzheimer's disease living in the community. Journal of the Neurological Sciences, 358, 77-81. 
Depression and burden in caregivers of people with dementia

Ramos-Brieva JC (1986) Validacion de la versión castellana de la escala de Hamilton para la depresión. Actas Luso-Esp Neurol Psquiatr, 6, 324-334.

Reisberg B, Ferris SH, de Leon MJ and Crook T (1982) The Global Deterioration Scale for assessment of primary degenerative dementia. American Journal of Psychiatry, 139, $1136-1139$.

Riedel O, Klotsche J and Wittchen HU (2016) Overlooking informal dementia caregivers' burden. Research in Gerontological Nursing, 9, 167-174.

Roche L, Croot K, MacCann C, Cramer B and Diehl-Schmid J (2015) The role of coping strategies in psychological outcomes for frontotemporal dementia caregivers. Journal of Geriatric Psychiatry and Neurology, 28, 218-228.

Rosenthal R (1979) The file drawer problem and tolerance for null results. Psychological Bulletin, 86, 638-341.

Rosness TA, Mjørud M and Engedal K (2011) Quality of life and depression in carers of patients with early onset dementia. Aging \& Mental Health, 15, 299-306.

Roth DL, Ackerman ML, Okonkwo OC and Burgio LD (2008) The four-factor model of depressive symptoms in dementia caregivers: A structural equation model of ethnic differences. Psychology and Aging, 23, 567-576.

Roth M, Tym E, Mountjoy CQ, Huppert FA, Hendrie H, Verma S, and Goddard R (1986) CAMDEX. A standardised instrument for the diagnosis of mental disorder in the elderly with special reference to the early detection of dementia. The British Journal of Psychiatry, 149, 698-709. 
Depression and burden in caregivers of people with dementia

Sallim AB, Sayampanathan AA, Cuttilan A and Ho RCM (2015) Prevalence of mental health disorders among caregivers of patients with Alzheimer disease. Journal of the American Medical Directors Association, 16, 1034-1041.

Sansoni J, Vellone E and Piras G (2004) Anxiety and depression in community-dwelling, Italian Alzheimer's disease caregivers. International Journal of Nursing Practice, 10, 93-100.

Schulz R and Martire LM (2004) Family caregiving of persons with dementia: prevalence, health effects, and support strategies. The American Journal of Geriatric Psychiatry, 12, 240-249.

Simpson CE (2010) Sleep: effect on dementia caregiver mastery, perceived stress and depression (unpublished doctoral dissertation). The University of Texas at Austin, Austin, TX.

Slachevsky A, Budinich M, Miranda-Castillo C, Nunez-Huasaf J, Silva JR, Munoz-Neira C, Gloger S, Jimenez O, Martorell B and Delgado C (2013) The CUIDEME Study: determinants of burden in chilean primary caregivers of patients with dementia. Journal of Alzheimer's Disease, 35, 297-306.

Sleath B, Thorpe J, Landerman LR, Doyle M and Clipp E (2005). African-American and White Caregivers of Older Adults with Dementia: Differences in Depressive Symptomatology and Psychotropic Drug Use. Journal of the American Geriatrics Society, 53, 397-404.

Spector A, Thorgrimsen L, Woods BOB, Royan L, Davies S, Butterworth M and Orrell M (2003) Efficacy of an evidence-based cognitive stimulation therapy programme for people with dementia. The British Journal of Psychiatry, 183, 248-254. 
Depression and burden in caregivers of people with dementia

Spitzer RL and Robins E (1978) Research diagnostic criteria: rationale and reliability. Archives of General Psychiatry, 35, 773-782

Taylor Nelson Sofres British Market Research Bureau Limited (2014) Attitudes to mental illness: 2013 research report. Retrieved from, https://www.mind.org.uk/newscampaigns/news/survey-shows-greatest-improvement-in-public-attitudes-to-mentalhealth-in-20-years/\#.WmUMqKhl-00

Välimäki TH, Martikainen JA, Hallikainen IT, Väätäinen ST and Koivisto AM (2015) Depressed spousal caregivers have psychological stress unrelated to the progression of Alzheimer disease: a 3-year follow-up report, Kuopio ALSOVA study. Journal of Geriatric Psychiatry and Neurology, 28, 272-280.

Vitaliano PP, Young HM and Russo J (1991) Burden: A review of measures used among caregivers of individuals with dementia. The Gerontologist, 31, 67-75.

Vitaliano PP (1997) Physiological and physical concomitants of caregiving: Introduction to special issue. Annals of Behavioral Medicine, 19, 75-77.

Waite A, Bebbington P, Skelton-Robinson M and Orrell M (2004) Social factors and depression in carers of people with dementia. International Journal of Geriatric Psychiatry, 19, 582-587.

Wang J, Wu X, Lai W, Long E, Zhang X, Li W, Zhu Y, Chen C, Zhong X, Liu Z and Wang D (2017) Prevalence of depression and depressive symptoms among outpatients: a systematic review and meta-analysis. BMJ Open, 7, 017173.

Williams IC (2005) Emotional health of black and white dementia caregivers: A contextual examination. The Journals of Gerontology Series B: Psychological Sciences and Social Sciences, 60, 287-295. 
Depression and burden in caregivers of people with dementia

Williamson GM and Schulz R (1993) Coping with specific stressors in Alzheimer's disease caregiving. The Gerontologist, 33, 747-755.

Wittchen HU, Höfler M and Meister W (2001) Prevalence and recognition of depressive syndromes in German primary care settings: Poorly recognized and treated? International Clinical Psychopharmacology, 16, 121-135.

World Health Organization (1978) The ICD-9 classification of mental and behavioural disorders: Clinical descriptions and diagnostic guidelines. Geneva: World Health Organization.

World Health Organization (1992) The ICD-10 classification of mental and behavioural disorders: Clinical descriptions and diagnostic guidelines. Geneva: World Health Organization.

World Health Organization (2003) International Classification of Primary Care, Second edition (ICPC-2). Retrieved from http://www.who.int/classifications/icd/adaptations/icpc2/en/index.

World Health Organization (2017) Depression and other common mental disorders: global health estimates. Geneva, Switzerland: WHO Document Production Services.

Yesavage JA and Sheikh JI (1986) Geriatric depression scale (GDS) recent evidence and development of a shorter version. Clinical Gerontologist, 5, 165-173.

Yesavage JA, Brink TL, Rose TL, Lum O, Huang V, Adey M and Leirer VO (1983) Development and validation of a geriatric depression screening scale: a preliminary report. Journal of Psychiatric Research, 17, 37-49. 
Depression and burden in caregivers of people with dementia

Zarit SH, Reever KE and Back-Peterson J (1980) Relatives of the impaired elderly: correlates of feelings of burden. The Gerontologist, 20, 649-655.

Zarit SH, Todd PA and Zarit JM (1986) Subjective burden of husbands and wives as caregivers: A longitudinal study. The Gerontologist, 26, 260-266.

Zigmond AS and Snaith RP (1983) The hospital anxiety and depression scale. Acta Psychiatrica Scandinavica, 67, 361-370. 


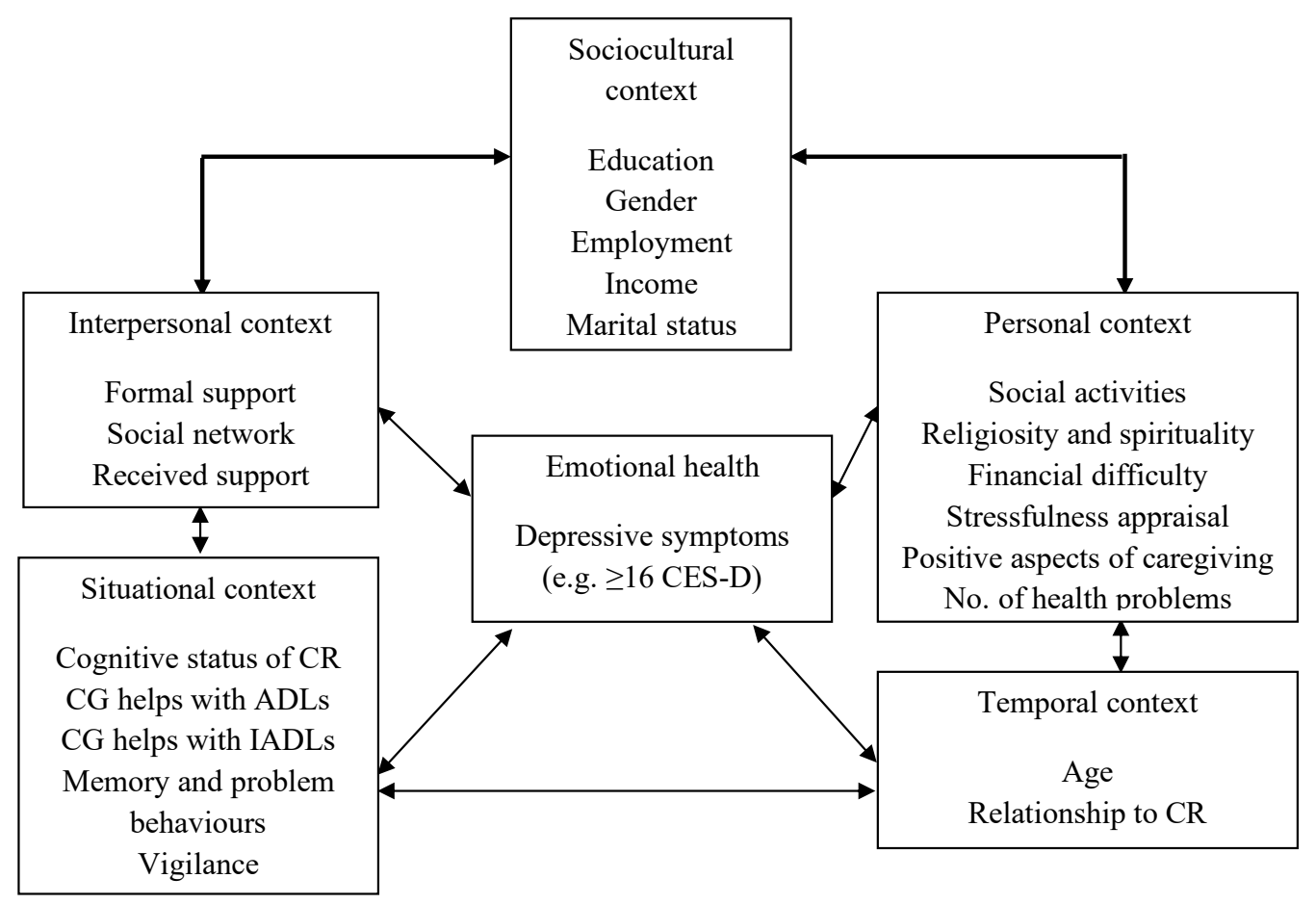

Fig 1. The conceptual model for understanding the effects of context on emotional health outcomes among caregivers of people with dementia, adapted from the model of Dilworth-Anderson and Anderson (1994). CES-D = Center for Epidemiological Studies-Depression Scale; CR = care recipient; $\mathrm{CG}=$ caregiver; $\mathrm{ADLs}=$ activities of daily living; IADLs $=$ instrumental ADLs. 


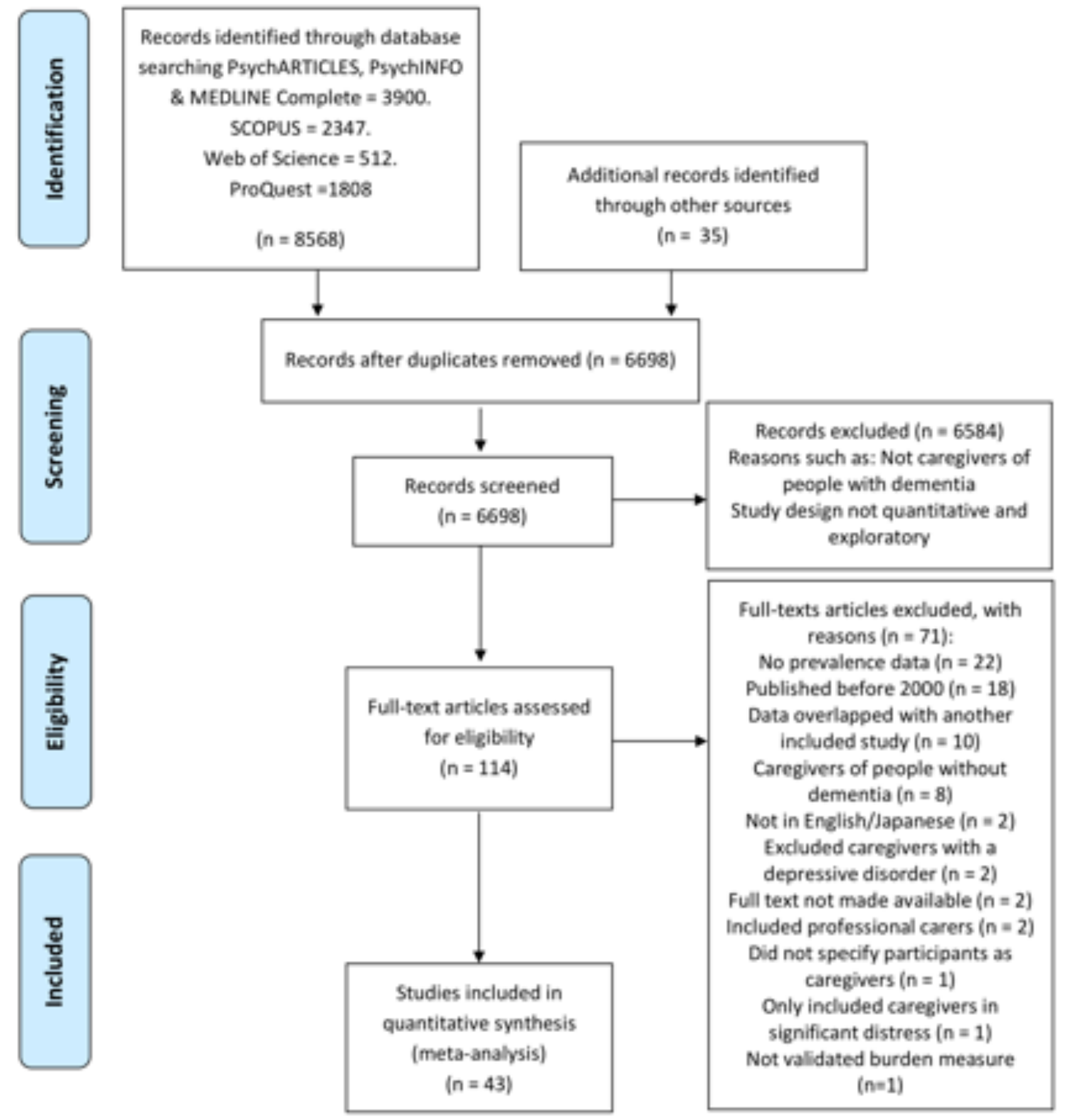

Fig.2. PRISMA flowchart of information from identification to inclusion of studies. 


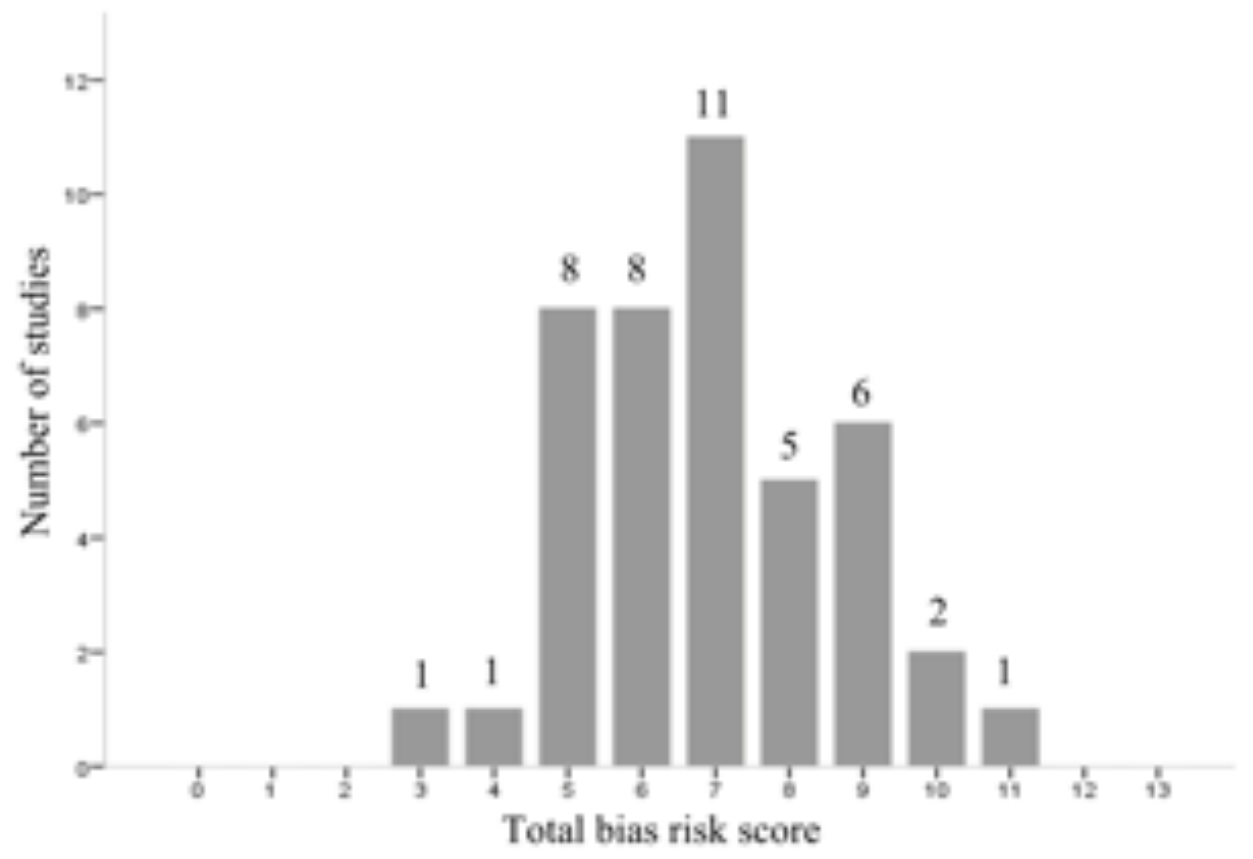

Fig. 3a. Bias risk assessment of 43 studies: number of studies per rating

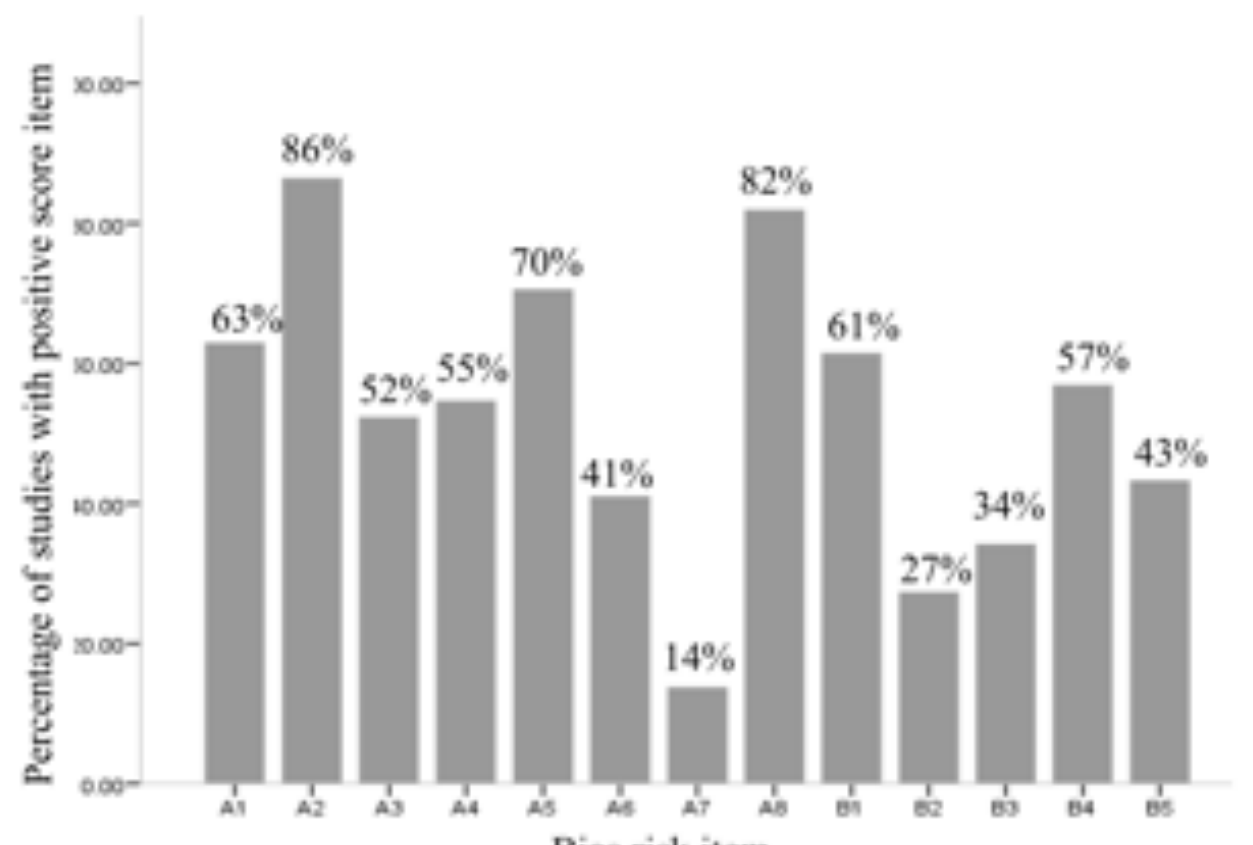

Bias risk item

Fig. 3b. The percentage of studies with a positive score on each risk item. 
Adrms ex a (2002)

varue ed (2009)

bodurat es (201)

Cejiei as (20)e)

Dargr atd (2006)

Doriesal 2016

Canpr and ORarke (2009)

Cleng ad (2013)

Corads $=d(20+2)$

Covirshy as a (2000)

Cucoire as $A$ (2010)

Galuge at a (2011)

Groia Nberca ed (2012)

Grers a al (2014)

Hropanasta (2014)

Holand et a (2010)

miged al (2004)

Kaser and Propres (2007)

Kurz at a (2003)

Lian as a (2016)

owery ax $(2000)$

Luand Autrom (2006)

Luchingy at a (2015)

Maroney atd (2005)

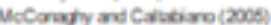

Votroes a (2014)

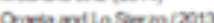

Oatic es a (2014)

Pery as (2013)

Riadi as $a$ (2016)

Rocted a d (2015)

Rowess af a (201)

Rothes a (200)

Srovi at $d$ (2014)

Simpson (2010)

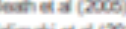

Xlimati at a $(2015)$

Wometa d (2004)

\begin{tabular}{|c|c|c|c|c|}
\hline $\begin{array}{c}\text { Event } \\
\text { nate }\end{array}$ & $\begin{array}{l}\text { Loune } \\
\text { init }\end{array}$ & Upper & 2 -value & p-valut \\
\hline 0.302 & 0.203 & 0.26 & -5.067 & 0.000 \\
\hline 0.397 & 0.292 & 0.513 & -1.740 & 0.065 \\
\hline 0.390 & 0.258 & o.ses & -1.994 & Q.160 \\
\hline$a, x$ & 0.100 & 0.162 & -12988 & 0.00 \\
\hline 0.267 & 0.150 & 0.413 & 3001 & 0.000 \\
\hline 0.231 & 0.160 & 0.316 & -5.487 & 0.000 \\
\hline Q.19 & 0.10 & 0.167 & $20 \mathrm{sec}$ & 0.000 \\
\hline 0.275 & 0.200 & 0.35 & -5. ses & 0.000 \\
\hline $0 \times 2$ & 0.254 & 0.48 & 2115 & 0.002 \\
\hline 0.020 & 0.06 & 0.200 & $26 x$ & 0.000 \\
\hline a.169 & 0.104 & 0.281 & -5008 & 0.000 \\
\hline 0.303 & 0.261 & 0.400 & 2986 & 0.000 \\
\hline 0.506 & 0.028 & 0.603 & 0.670 & 0.500 \\
\hline 0.23 & 0.178 & 0.200 & -7341 & 0.00 \\
\hline 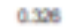 & 0.252 & 0.200 & 3867 & 0000 \\
\hline 0.258 & 0.302 & 0609 & 0.437 & 0.602 \\
\hline 0.459 & 0.345 & 0.597 & 2006 & 0.049 \\
\hline 0.520 & 0.02 & 0.000 & 1396 & a.162 \\
\hline 0.286 & 0.38 & 0.087 & 2004 & 0.042 \\
\hline 0.209 & 0.149 & 0.294 & 600 & 0.000 \\
\hline $00 x$ & 0010 & ocose & 5900 & 0.000 \\
\hline 0.20 & 0.20 & 0.36 & $4 \cos$ & 0.00 \\
\hline 0.511 & 0.08 & 0.505 & 0.254 & 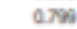 \\
\hline a.tos & 0.065 & Q.164 & -8128 & 0,000 \\
\hline o.s9s & 0.40 & Q & $122 \mathrm{~m}$ & 0.20 \\
\hline 0.630 & $0 \times 0$ & 0.553 & -1096 & 0.27 \\
\hline 0.547 & $0.4 n$ & 0,000 & 1225 & 0.200 \\
\hline 0.267 & 2.19 & 0.050 & .2450 & 0.054 \\
\hline Q.164 & 0.126 & 0.215 & 964 & 0.00 \\
\hline 0.437 & $0 x$ & $0 \cos x$ & 2534 & 0.011 \\
\hline Q.4099 & 0.990 & 0 ses & .0206 & 0.837 \\
\hline 0.501 & 0.000 & ocoss & 0.020 & 0.000 \\
\hline 0.490 & $0 \times 2$ & 0.00 & e.15a & 0.000 \\
\hline 0.59 & 0.065 & 0.603 & 0.300 & orse \\
\hline 35 & 0.221 & & 3209 & 0009 \\
\hline 0.390 & 0.000 & 0.00 & -9607 & 0.000 \\
\hline 0.411 & $0 \times 0$ & 0.517 & -1.500 & $0.12 x$ \\
\hline 0.431 & 0.202 & 0.587 & $=1.175$ & 0.290 \\
\hline $92 x$ & $0 \times 99$ & 0.75 & -7812 & 0,000 \\
\hline
\end{tabular}

$\mid$
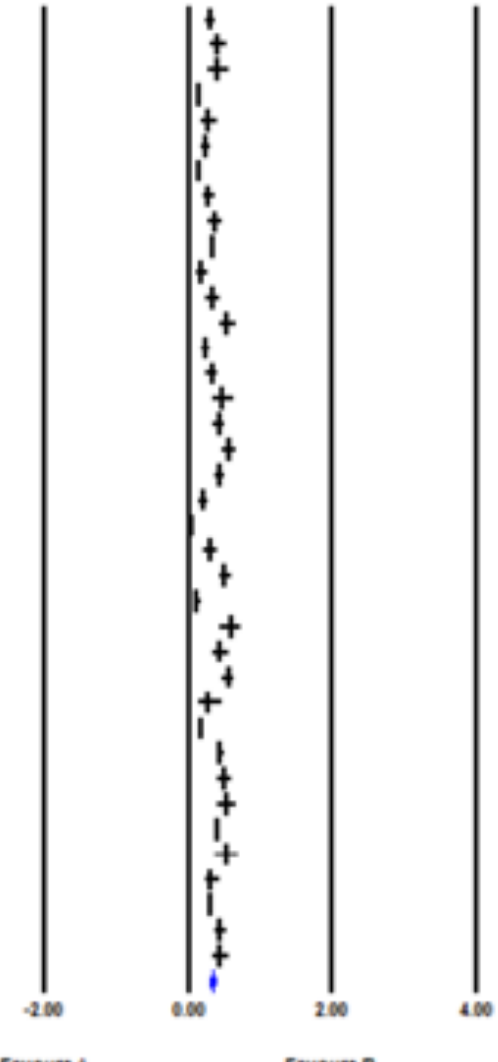

Fig 4. Forest plot on the prevalence of depression among caregivers of people with dementia. 
Study name

Arango et al (2609)

Brodaty et al (2014)

Germain ef al (2009)

Luchsinger et al (2015)

UeConashy and Catabiano (2005)

Medrano et al (2014)

Raggi et al (2015)

Slachevsky et al (2013)

Ebstein-Lubow et al (2009)
Statistics for each study

\begin{tabular}{|c|c|c|c|c|}
\hline $\begin{array}{c}\text { Event } \\
\text { rate }\end{array}$ & $\begin{array}{l}\text { Lower } \\
\text { limit }\end{array}$ & $\begin{array}{l}\text { Upper } \\
\text { limit }\end{array}$ & Z.Value & p.Value \\
\hline 0.605 & 0.570 & 0.7 t & 3.062 & 0.002 \\
\hline 0.500 & 0.457 & 0.543 & 0.000 & 1.060 \\
\hline 0.450 & 0.421 & 0.430 & -3.294 & 0.001 \\
\hline o.tes & 0.020 & $0.92 t$ & 7.674 & 0.060 \\
\hline 0.786 & 0.637 & 0.835 & 3.455 & 0.001 \\
\hline 0.358 & 0.253 & 0.479 & -2269 & 0.022 \\
\hline 0.603 & 0.487 & 0.708 & 1.743 & 0.081 \\
\hline 0.742 & 0.689 & 0.789 & 7.692 & 0.060 \\
\hline 0.455 & 0.296 & 0.623 & -0.522 & 0.602 \\
\hline 0.621 & 0.512 & 0.720 & 2.162 & 0.031 \\
\hline
\end{tabular}

\section{Event rate and $95 \% \mathrm{Cl}$}

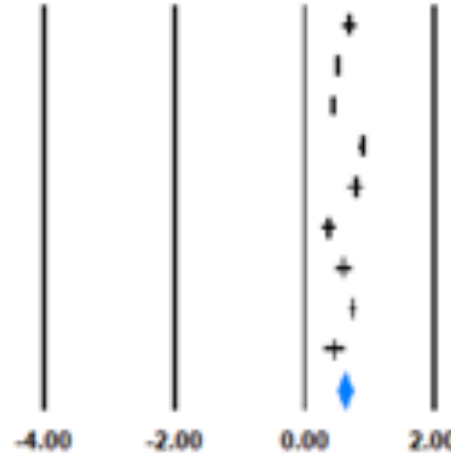

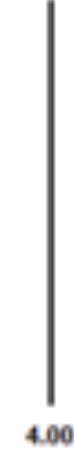

Fig 5. Forest plot on the prevalence of burden among caregivers of people with dementia. 


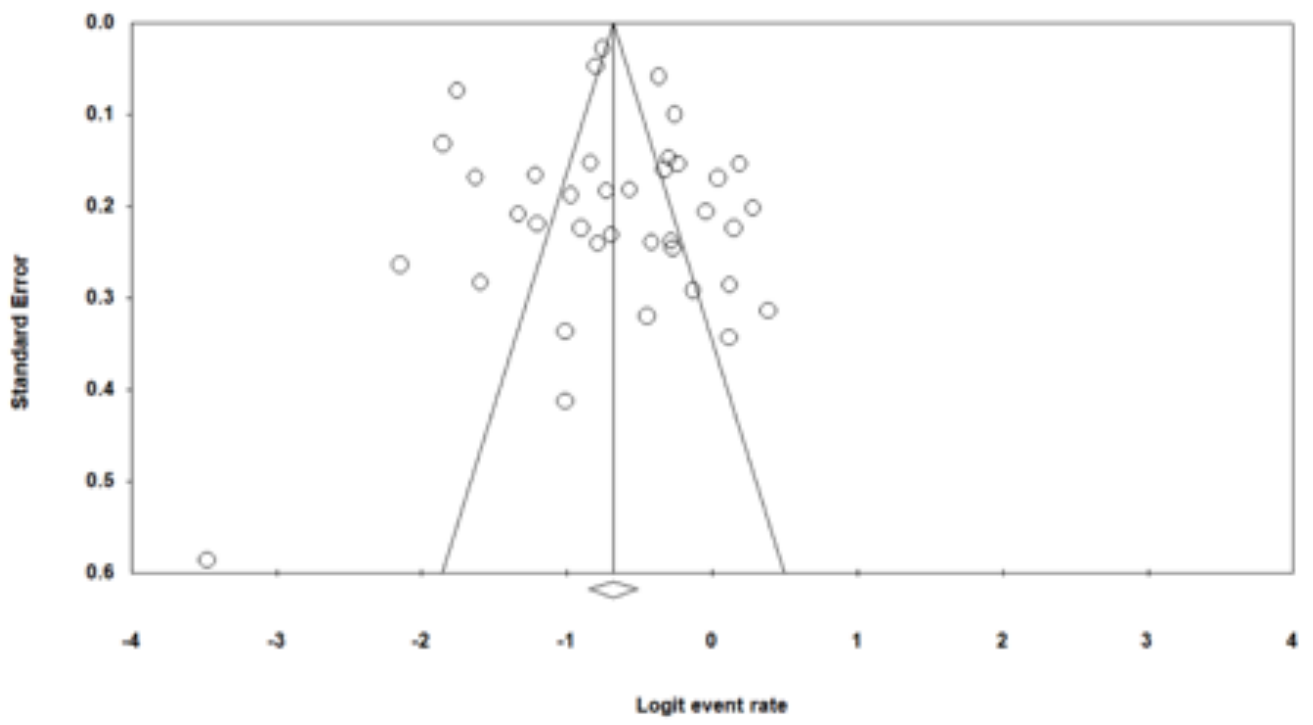

Fig 6. Random effects funnel plot of logit event rate depression effect sizes by standard error. 


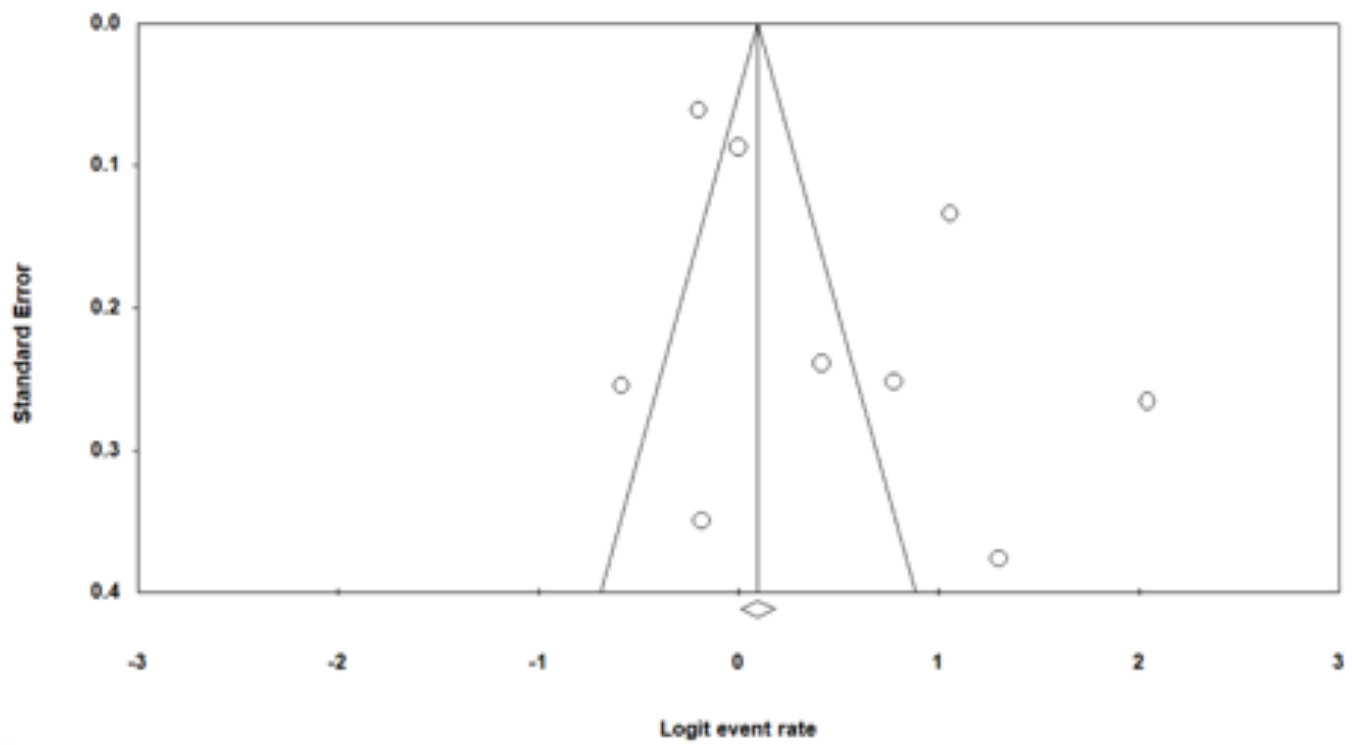

Fig 7. Random effects funnel plot of logit event rate burden effect sizes by standard error. 
Table 1. Search strategy and key terms

Concepts Search terms

\begin{tabular}{l}
\hline Epidemiology1 \\
OR ‘inciden*'
\end{tabular}

Burden/depression² 'depress*' OR ‘depression emotion' OR 'distress' OR 'depressive disorder’ OR ‘major depression’ OR ‘burden’

\begin{tabular}{ll}
\hline Type of participants ${ }^{3}$ & 'Dementia' OR ‘Alzheimer’s' OR ‘cognitively impaired' OR \\
& 'caregiver' OR 'carer' OR ‘care' OR ‘caring' OR ‘caregiving' OR \\
& 'family caregiver' OR ‘family carer' OR ‘informal caregiver' OR \\
& 'informal carer'
\end{tabular}

Combined 12 AND 3

Note: For the databases PsycARTICLES, PsycINFO and MEDLINE Complete the key words in the 'epidemiology concept' were searched for in the abstracts of texts and the 'burden/depression' and 'participants' concepts in the title of texts. The SCOPUS search was limited to articles, reviews and conference papers, and all key words were searched for in the titles and abstracts of articles. The key words were searched for in the titles of texts within the Web of Science database and abstracts of texts within the Proquest database. 
Table 2. 13-item adapted bias risk assessment tool

\begin{tabular}{lll}
\hline Bias Risk Item & Positive Score & Negative Score \\
Study: & $(1)$ : Adequate & $(0)$ incomplete, \\
& information is & $\begin{array}{l}\text { unclear or lack } \\
\text { of description }\end{array}$ \\
\hline
\end{tabular}

A. Patient population

1. Socio-demographic descriptions are described including age, gender, marital status or educational/employment/socioeconomic status

2. Inclusion and exclusion criteria are formulated

3. Type and percentage of the different forms of dementia

4. Diagnostic procedure used to identify probable dementia

5. Range or mean and SD of dementia severity in sample is described

6. Mean or median and range or standard deviation of time as carer given

7. (History of) psychiatric problems are detailed

8. Percentages of the types of relationship to person with dementia is given

B. Sample recruitment

1. Sample size $\geq 100$

2. Participation and response rates are described and are more than $75 \%$

3. Reasons for non-response or nonparticipation are described or there is a comparison between responders and nonresponders

4. Description of recruitment method, period of recruitment and place of recruitment (setting and geographical location

5. Consecutive sample (sought to include all accessible subjects)

Total: 5 (high risk)

Divide total by 13:

Risk: low risk, medium risk or high risk

Note: low risk $=\geq 9.75$ medium risk $=\geq 6.5-9.75$ high risk $=<6.5$ 
Table 3: Characteristics of included studies $(\mathrm{N}=43)$

\begin{tabular}{|c|c|c|c|c|c|c|c|c|}
\hline Study & Location & Design & $\begin{array}{l}\text { Recruitment } \\
\text { source }\end{array}$ & $\begin{array}{c}\text { Dementia diagnostic } \\
\text { procedure }\end{array}$ & Forms of dementia & $n$ & $\begin{array}{c}\bar{x} \\
\text { age }\end{array}$ & $\%$ q \\
\hline Adams et al. (2002) & $\begin{array}{c}\text { USA; CA } \\
\text { and Hawaii }\end{array}$ & $\begin{array}{c}\text { Cross- } \\
\text { sectional }\end{array}$ & $\begin{array}{l}\text { Senior centre, } \\
\text { rehab centre and } \\
\text { agencies of the } \\
\text { USC }\end{array}$ & $\mathrm{N} / \mathrm{A}$ & $\mathrm{N} / \mathrm{A}$ & 202 & 74.9 & $67.3 \%$ \\
\hline Arango et al. (2009) & $\begin{array}{l}\text { South } \\
\text { America; } \\
\text { Columbia }\end{array}$ & $\begin{array}{c}\text { Cross- } \\
\text { sectional }\end{array}$ & A memory clinic & $\mathrm{N} / \mathrm{A}$ & N/A & 73 & 57.7 & $82.2 \%$ \\
\hline Bednarek et al. (2016) & $\begin{array}{l}\text { Poland; } \\
\text { Greater } \\
\text { Poland }\end{array}$ & $\begin{array}{l}\text { Baseline } \\
\text { RCT data }\end{array}$ & $\begin{array}{l}\text { A project aimed to } \\
\text { understand and } \\
\text { support caregivers } \\
\text { of PwD }\end{array}$ & $\begin{array}{c}\text { Medically } \\
\text { diagnosed; unknown } \\
\text { procedure }\end{array}$ & N/A & 41 & 61.7 & $73.2 \%$ \\
\hline Bejjani et al. (2016) & $\begin{array}{l}\text { USA; MA, } \\
\text { TX, RI and } \\
\quad \text { OK }\end{array}$ & $\begin{array}{l}\text { Baseline } \\
\text { RCT data }\end{array}$ & $\begin{array}{l}\text { Veterans' admin } \\
\text { health care system }\end{array}$ & $\mathrm{N} / \mathrm{A}$ & N/A & 486 & 68.4 & $94 \%$ \\
\hline Berger et al. (2005) & $\begin{array}{l}\text { Germany; } \\
\text { Frankfurt }\end{array}$ & $\begin{array}{l}\text { Longitudinal } \\
\text { prospective } \\
\text { cohort }\end{array}$ & A memory clinic & $\begin{array}{l}\text { Neurological and } \\
\text { neuropsy-chological } \\
\text { assessment in line } \\
\text { with ICD-10 }\end{array}$ & $\begin{array}{c}\text { AD } 72 \% \\
\text { VD 9\% } \\
\text { FTD 9\% } \\
\text { Mixed dementia } \\
4 \%\end{array}$ & 45 & 60.7 & $62 \%$ \\
\hline
\end{tabular}


Unknown 4\%

LBD 2\%

\begin{tabular}{|c|c|c|c|c|c|c|c|c|}
\hline Borsje et al. (2016) & $\begin{array}{l}\text { Netherlands } \\
\text {; Southern } \\
\text { regions }\end{array}$ & $\begin{array}{l}\text { Longitudinal } \\
\text { prospective } \\
\text { cohort }\end{array}$ & $\begin{array}{l}\text { General } \\
\text { Practitioner } \\
\text { surgeries }\end{array}$ & ICPC-2 & N/A & 117 & 67.3 & $68.4 \%$ \\
\hline Brodaty et al. (2014) & $\begin{array}{l}\text { Australia; } \\
\text { multiple } \\
\text { locations }\end{array}$ & $\begin{array}{l}\text { Longitudinal } \\
\text { prospective } \\
\text { cohort }\end{array}$ & $\begin{array}{l}\text { Three memory } \\
\text { clinics }\end{array}$ & $\begin{array}{c}\text { DSM-IV criteria for } \\
\text { dementia }\end{array}$ & $\begin{array}{c}\text { AD 71.2\% } \\
\text { VD 7\% } \\
\text { FTD } 4.2 \% \\
\text { Mixed dementia } \\
17.6 \%\end{array}$ & 524 & N/A & $64.9 \%$ \\
\hline $\begin{array}{l}\text { Caspar and O'Rourke } \\
\text { (2009) }\end{array}$ & $\begin{array}{c}\text { Canada; all } \\
\text { provinces } \\
\text { except } \\
\text { Ontario }\end{array}$ & $\begin{array}{c}\text { Cross- } \\
\text { sectional }\end{array}$ & $\begin{array}{l}\text { Government } \\
\text { health records }\end{array}$ & $\begin{array}{c}\text { MMSE, } \\
\text { neurological and } \\
\text { neuropsyc-hological } \\
\text { assessment }\end{array}$ & N/A & 1426 & N/A & N/A \\
\hline Cheng et al. (2013) & $\begin{array}{c}\text { China, } \\
\text { Hong Kong }\end{array}$ & $\begin{array}{c}\text { Cross- } \\
\text { sectional }\end{array}$ & $\begin{array}{l}\text { Memory clinics, } \\
\text { outpatient clinics, } \\
\text { day hospitals, day } \\
\text { care centres and } \\
\text { social services }\end{array}$ & $\begin{array}{l}\text { NINCDS-ADRDA } \\
\text { criteria for AD }\end{array}$ & AD $100 \%$ & 142 & 58.9 & $73 \%$ \\
\hline
\end{tabular}




\begin{tabular}{|c|c|c|c|c|c|c|c|c|}
\hline Contador et al. (2012) & $\begin{array}{c}\text { Spain; } \\
\text { Salamanca }\end{array}$ & $\begin{array}{c}\text { Cross- } \\
\text { sectional }\end{array}$ & $\begin{array}{l}\text { Referrals to the } \\
\text { Association of } \\
\text { Family Members } \\
\text { of Patients with } \\
\text { Alzheimer's }\end{array}$ & $\begin{array}{c}\text { DSM-IV-R for } \\
\text { dementia }\end{array}$ & $\begin{array}{c}\text { AD } 40.8 \% \\
\text { VD } 28.4 \% \\
\text { Mixed dementia } \\
30.8 \%\end{array}$ & 130 & 58.6 & $72 \%$ \\
\hline Covinsky et al. (2003) & $\begin{array}{l}\text { USA; MN, } \\
\text { FL, OR, } \\
\text { NY, TN, } \\
\text { OH and IL }\end{array}$ & $\begin{array}{l}\text { Baseline } \\
\text { RCT data }\end{array}$ & $\begin{array}{c}\text { Physician referrals } \\
\text { and self-referrals }\end{array}$ & N/A & $\mathrm{N} / \mathrm{A}$ & 5627 & 64 & $71.7 \%$ \\
\hline Cucciare et al (2010) & USA; CA & $\begin{array}{l}\text { Baseline } \\
\text { RCT data }\end{array}$ & $\begin{array}{l}\text { Health and social } \\
\text { services } \\
\text { professionals, } \\
\text { media, and word } \\
\text { of mouth }\end{array}$ & $\begin{array}{l}\text { Physician diagnosis } \\
\text { or MMSE below } 23\end{array}$ & $\mathrm{~N} / \mathrm{A}$ & 89 & 51.8 & $100 \%$ \\
\hline $\begin{array}{l}\text { Epstein-Lubow et al. } \\
(2008)\end{array}$ & $\begin{array}{l}\text { USA, New } \\
\text { England }\end{array}$ & $\begin{array}{l}\text { Baseline } \\
\text { RCT data }\end{array}$ & $\begin{array}{l}\text { Memory clinics, } \\
\text { support groups } \\
\text { and media }\end{array}$ & $\begin{array}{l}\text { DSM-IV for } \\
\text { dementia and } \\
\text { Clinical Dementia } \\
\text { Rating of mild or } \\
\text { moderate }\end{array}$ & N/A & 33 & N/A & $79 \%$ \\
\hline Gallagher et al (2011) & $\begin{array}{l}\text { Ireland, } \\
\text { Dublin }\end{array}$ & $\begin{array}{c}\text { Cross- } \\
\text { sectional }\end{array}$ & A memory clinic & $\begin{array}{c}\text { DSM-IV-R, } \\
\text { NINCDS-ADRDA, } \\
\text { neurological and } \\
\text { neuropsychological } \\
\text { assessment }\end{array}$ & $\mathrm{AD} 100 \%$ & 84 & 63.3 & $57.1 \%$ \\
\hline
\end{tabular}




\begin{tabular}{|c|c|c|c|c|c|c|c|c|}
\hline $\begin{array}{l}\text { García-Alberca et al } \\
\text { (2012) }\end{array}$ & $\begin{array}{l}\text { Spain, } \\
\text { Malaga }\end{array}$ & $\begin{array}{c}\text { Cross- } \\
\text { sectional }\end{array}$ & $\begin{array}{l}\text { Local health } \\
\text { services and the } \\
\text { voluntary sector }\end{array}$ & $\begin{array}{c}\text { NINCDS-ADRDA } \\
\text { criteria for AD }\end{array}$ & $\mathrm{AD} 100 \%$ & 80 & 62.2 & $77.5 \%$ \\
\hline Germain et al. (2009) & $\begin{array}{l}\text { Belgium, } \\
\text { Denmark, } \\
\text { France, UK, } \\
\text { Germany, } \\
\text { Greece, } \\
\text { Italy, The } \\
\text { Netherlands } \\
\text {, Romania, } \\
\text { Spain, } \\
\text { Sweden } \\
\text { Switzerland }\end{array}$ & $\begin{array}{c}\text { Cross } \\
\text { sectional } \\
\text { using data } \\
\text { from a } \\
\text { longitudinal } \\
\text { prospective } \\
\text { cohort study }\end{array}$ & $\begin{array}{c}29 \text { specialist } \\
\text { outpatient clinics }\end{array}$ & $\begin{array}{c}\text { NINCDS-ADRDA } \\
\text { criteria for AD }\end{array}$ & $\mathrm{AD} 100 \%$ & 1091 & 62.3 & $63.5 \%$ \\
\hline
\end{tabular}

\begin{tabular}{|c|c|c|c|c|c|c|c|}
\hline Givens et al. (2014) & $\begin{array}{l}\text { USA; MN, } \\
\text { OR, PA }\end{array}$ & $\begin{array}{c}\text { Cross } \\
\text { sectional } \\
\text { using a } \\
\text { longitudinal } \\
\text { prospective } \\
\text { cohort study }\end{array}$ & $\begin{array}{c}\text { "Population based } \\
\text { listings" }\end{array}$ & $\begin{array}{l}\text { None caregiver self- } \\
\text { report }\end{array}$ & $\mathrm{N} / \mathrm{A}$ & 206 & 82.4 \\
\hline
\end{tabular}




\begin{tabular}{|c|c|c|c|c|c|c|c|c|}
\hline Hasegawa et al. (2014) & $\begin{array}{c}\text { Japan; } \\
\text { Kumamoto } \\
\text { city on the } \\
\text { island of } \\
\text { Kyushu }\end{array}$ & $\begin{array}{c}\text { Cross- } \\
\text { sectional }\end{array}$ & $\begin{array}{l}\text { Two memory } \\
\text { clinics }\end{array}$ & $\begin{array}{l}\text { Neurological and } \\
\text { neuropsychological } \\
\text { assessments and } \\
\text { DSM-III-R for } \\
\text { dementia. }\end{array}$ & $\begin{array}{c}\text { AD } 62.2 \% \\
\text { VD } 16.3 \% \\
\text { LBD } 14.1 \% \\
\text { Other dementia } \\
\quad 7.4 \%\end{array}$ & 135 & N/A & $68.2 \%$ \\
\hline Holland et al. (2010) & $\begin{array}{c}\text { USA; San } \\
\text { Fransisco } \\
\text { Bay CA }\end{array}$ & $\begin{array}{l}\text { Cross- } \\
\text { sectional }\end{array}$ & $\begin{array}{c}\text { Media, and } \\
\text { professional and } \\
\text { non-professional } \\
\text { referrals }\end{array}$ & $\begin{array}{c}\text { MMSE } \leq 23 \text { or } \\
\text { documented } \\
\text { diagnosis }\end{array}$ & N/A & 47 & 59.5 & $100 \%$ \\
\hline Jang et al. (2004) & USA; NY & $\begin{array}{l}\text { Baseline } \\
\text { RCT data }\end{array}$ & $\begin{array}{c}\text { Alzheimer's } \\
\text { Disease centre, } \\
\text { adult day care } \\
\text { services, social } \\
\text { services, and } \\
\text { media }\end{array}$ & N/A & N/A & 160 & NS & $61.5 \%$ \\
\hline $\begin{array}{l}\text { Kaiser and Panegyres } \\
\text { (2007) }\end{array}$ & $\begin{array}{l}\text { Australia; } \\
\text { Perth }\end{array}$ & $\begin{array}{l}\text { Cross- } \\
\text { sectional }\end{array}$ & $\begin{array}{l}\text { Neuroscience } \\
\text { assessment and } \\
\text { care clinic }\end{array}$ & $\begin{array}{l}\text { NINCDS-ADRDA } \\
\text { criteria for AD, } \\
\text { consensus criteria } \\
\text { for FTD and PPA }\end{array}$ & $\begin{array}{c}\text { FTD } 42 \% \\
\text { AD } 36 \% \\
\text { Primary } \\
\text { Progressive } \\
\text { Aphasia } 6 \% \\
\text { Other dementia } \\
16 \%\end{array}$ & 100 & 62.3 & $54 \%$ \\
\hline
\end{tabular}




\begin{tabular}{|c|c|c|c|c|c|c|c|c|}
\hline Kurz et al. (2003) & $\begin{array}{l}\text { Belgium, } \\
\text { multiple } \\
\text { locations }\end{array}$ & $\begin{array}{c}\text { Cross- } \\
\text { sectional }\end{array}$ & $\begin{array}{c}\text { General } \\
\text { practitioners, } \\
\text { specialists and } \\
\text { psychologists. }\end{array}$ & $\begin{array}{l}\text { CAMDEX and } \\
\text { diagnosed in line } \\
\text { with DSM-III-R }\end{array}$ & N/A & 188 & N/A & $66.7 \%$ \\
\hline Liang et al. (2016) & $\begin{array}{l}\text { China; } \\
\text { Shanghai }\end{array}$ & $\begin{array}{c}\text { Cross- } \\
\text { sectional }\end{array}$ & A memory clinic & $\begin{array}{l}\text { Neuropsychological } \\
\text { assessments and } \\
\text { DSM-IV criteria for } \\
\text { dementia }\end{array}$ & $\mathrm{N} / \mathrm{A}$ & 139 & N/A & N/A \\
\hline Lowery et al. (2000) & $\begin{array}{c}\text { UK, } \\
\text { Tyneside } \\
\text { and } \\
\text { Birmming- } \\
\text { ham }\end{array}$ & $\begin{array}{c}\text { Cross- } \\
\text { sectional }\end{array}$ & $\begin{array}{l}\text { Two dementia } \\
\text { case register } \\
\text { cohorts }\end{array}$ & $\begin{array}{l}\text { Consensus criteria } \\
\text { for DLB and } \\
\text { NINCDS-ADRDA } \\
\text { for probable AD }\end{array}$ & $\begin{array}{c}25 \% \text { LBD } \\
75 \% \text { AD }\end{array}$ & 100 & 83.5 & $68 \%$ \\
\hline Lu and Austrom (2005) & USA; OH & $\begin{array}{c}\text { Cross- } \\
\text { sectional }\end{array}$ & $\begin{array}{c}\text { University } \\
\text { Alzheimer } \\
\text { Disease Center } \\
\text { Caregiver } \\
\text { Registry }\end{array}$ & N/A & $\mathrm{N} / \mathrm{A}$ & 97 & N/A & $73.2 \%$ \\
\hline
\end{tabular}




\begin{tabular}{|c|c|c|c|c|c|c|c|c|}
\hline $\begin{array}{l}\text { Luchsinger et al. } \\
\text { (2015) }\end{array}$ & USA, NY & $\begin{array}{l}\text { Baseline } \\
\text { RCT data }\end{array}$ & $\begin{array}{l}\text { Memory clinics, } \\
\text { physicians, health } \\
\text { fairs and talks, } \\
\text { support groups } \\
\text { and media }\end{array}$ & $\begin{array}{c}\text { Documented } \\
\text { diagnosis; unknown } \\
\text { procedure }\end{array}$ & N/A & 139 & 59.3 & $\mathrm{~N} / \mathrm{A}$ \\
\hline Mahoney et al. (2005) & $\begin{array}{l}\text { UK; } \\
\text { London and } \\
\text { South-East } \\
\text { regions }\end{array}$ & $\begin{array}{c}\text { Cross- } \\
\text { sectional }\end{array}$ & $\begin{array}{l}\text { Local psychiatric } \\
\text { services, the } \\
\text { voluntary sector, } \\
\text { nursing and } \\
\text { residential homes }\end{array}$ & $\begin{array}{c}\text { NINCDS-ADRDA } \\
\text { criteria for AD and } \\
\text { DSM-IV }\end{array}$ & $\mathrm{AD} 100 \%$ & 153 & 64 & $69.9 \%$ \\
\hline $\begin{array}{l}\text { McConaghy and } \\
\text { Caltabiano (2005) }\end{array}$ & $\begin{array}{l}\text { Australia, } \\
\text { North } \\
\text { Queensland }\end{array}$ & $\begin{array}{c}\text { Cross- } \\
\text { sectional }\end{array}$ & $\begin{array}{c}\text { Homecare } \\
\text { dementia services }\end{array}$ & $\begin{array}{l}\text { MMSE and other } \\
\text { methods N/A }\end{array}$ & N/A & 42 & 62 & $76.2 \%$ \\
\hline Medrano et al. (2014) & $\begin{array}{l}\text { Dominican } \\
\text { Republic; } \\
\text { multiple } \\
\text { locations }\end{array}$ & $\begin{array}{c}\text { Cross- } \\
\text { sectional }\end{array}$ & $\begin{array}{c}\text { A health database } \\
\text { of over } 1500 \\
\text { patients }\end{array}$ & $\begin{array}{l}\text { NINCDS-ADRDA } \\
\text { criteria for AD }\end{array}$ & AD $100 \%$ & 67 & 61 & $84 \%$ \\
\hline $\begin{array}{l}\text { Orgeta and Lo Sterzo } \\
\text { (2013) }\end{array}$ & $\begin{array}{l}\mathrm{UK} ; \\
\text { multiple } \\
\text { locations }\end{array}$ & $\begin{array}{c}\text { Cross- } \\
\text { sectional }\end{array}$ & $\begin{array}{l}\text { Local voluntary } \\
\text { sectors supporting } \\
\text { caregivers of PwD }\end{array}$ & N/A. & N/A & 170 & 62.4 & $81.2 \%$ \\
\hline
\end{tabular}




\begin{tabular}{|c|c|c|c|c|c|c|c|c|}
\hline Ostojic et al. (2014) & $\begin{array}{l}\text { Croatia, } \\
\text { Zagreb }\end{array}$ & $\begin{array}{c}\text { Cross- } \\
\text { sectional }\end{array}$ & $\begin{array}{l}\text { Psychiatric } \\
\text { hospital }\end{array}$ & $\begin{array}{c}\text { DSM-IV criteria for } \\
\text { AD }\end{array}$ & AD $100 \%$ & 30 & 57.7 & $73.3 \%$ \\
\hline Piercy et al. (2013) & USA; UT & $\begin{array}{c}\text { Cross } \\
\text { sectional } \\
\text { using data } \\
\text { from a } \\
\text { longitudinal } \\
\text { prospective } \\
\text { cohort study }\end{array}$ & N/A & N/A & $\begin{array}{c}\text { AD } 60 \% \\
\text { VD } 14 \% \\
\text { Other dementia } \\
16 \%\end{array}$ & 256 & 67.5 & $76 \%$ \\
\hline Raggi et al. (2015) & Italy; Sicily & $\begin{array}{c}\text { Cross- } \\
\text { sectional }\end{array}$ & $\begin{array}{l}\text { Outpatients in } \\
\text { community }\end{array}$ & $\begin{array}{l}\text { DSM-5 criteria for } \\
\text { AD, medical history, } \\
\text { neurological and } \\
\text { neuropsychological } \\
\text { assessments }\end{array}$ & $\mathrm{AD} 100 \%$ & 73 & $\mathrm{~N} / \mathrm{A}$ & N/A \\
\hline Riedel et al. (2016) & $\begin{array}{l}\text { Germany; } \\
\text { multiple } \\
\text { locations }\end{array}$ & $\begin{array}{c}\text { Cross- } \\
\text { sectional }\end{array}$ & $\begin{array}{c}\text { Referrals from } \\
\text { office-based } \\
\text { neurologists }\end{array}$ & MMSE & $\mathrm{AD} 100 \%$ & 403 & 62.1 & $69 \%$ \\
\hline
\end{tabular}




\begin{tabular}{|c|c|c|c|c|c|c|c|c|}
\hline Roche et al. (2015) & $\begin{array}{l}\text { Germany; } \\
\text { multiple } \\
\text { locations }\end{array}$ & $\begin{array}{c}\text { Cross- } \\
\text { sectional }\end{array}$ & $\begin{array}{l}\text { Caregiver support } \\
\text { groups, German } \\
\text { Alzheimer's } \\
\text { Association, and } \\
\text { German FTD } \\
\text { consortium }\end{array}$ & $\begin{array}{l}\text { Medical diagnosis; } \\
\text { procedure unknown }\end{array}$ & FTD $100 \%$ & 94 & 59.1 & $72.3 \%$ \\
\hline Rosness et al. (2011) & $\begin{array}{l}\text { Norway; } \\
\text { Oslo }\end{array}$ & $\begin{array}{c}\text { Cross- } \\
\text { sectional }\end{array}$ & A memory clinic & $\begin{array}{l}\text { ICD-10 criteria for } \\
\text { early onset } \\
\text { dementia, physical } \\
\text { and neurological } \\
\text { assessments }\end{array}$ & $\begin{array}{c}\text { AD } 77.6 \% \\
\text { FTD } 14.3 \% \\
\text { VD } 6.1 \% \\
\text { LBD } 2 \%\end{array}$ & 49 & 60.3 & $69.4 \%$ \\
\hline Roth et al. (2008) & $\begin{array}{l}\text { USA; AL } \\
\text { MA, TN, } \\
\text { FL, CA and } \\
\text { PA. }\end{array}$ & $\begin{array}{l}\text { Baseline } \\
\text { RCT data }\end{array}$ & $\begin{array}{c}\text { Multiple } \\
\text { community sites } \\
\text { and health social } \\
\text { agency settings }\end{array}$ & $\begin{array}{l}\text { Medical diagnosis of } \\
\text { probable AD or } \\
\text { related dementia } \\
\text { (unknown } \\
\text { procedure) or } \\
\text { MMSE }<24\end{array}$ & N/A & 1183 & 62.2 & $81.5 \%$ \\
\hline Sansoni et al. (2014) & $\begin{array}{c}\text { Italy; Rome, } \\
\text { Florence } \\
\text { and Genoa }\end{array}$ & $\begin{array}{c}\text { Cross- } \\
\text { sectional }\end{array}$ & $\begin{array}{l}\text { Three ambulatory } \\
\text { care clinics }\end{array}$ & $\mathrm{N} / \mathrm{A}$ & N/A & 34 & 59.2 & $100 \%$ \\
\hline
\end{tabular}


Simpson (2010)

Slachevsky et al. (2013)

Sleath et al. (2005)

Valimaki et al. (2015)

\begin{tabular}{|c|c|c|}
\hline USA; TX & $\begin{array}{c}\text { Cross- } \\
\text { sectional }\end{array}$ & $\begin{array}{c}\text { Flyers distributed } \\
\text { by a geriatric } \\
\text { psychiatric } \\
\text { service, support } \\
\text { groups, respite } \\
\text { care and outreach } \\
\text { educational } \\
\text { programmes }\end{array}$ \\
\hline
\end{tabular}

Chile; $\quad$ Cross-
primarily
Santiago
primary care centres, neurological consultations and support groups.

$\begin{array}{lccc}\text { USA; } & \text { Cross- } & \text { A national } & \text { ICD-9 criteria for } \\ \text { multiple } & \text { sectional } & \text { database } & \text { AD or VD } \\ \text { locations } & & \\ \text { and Puerto } & & \\ \text { Rico } & & \end{array}$

$\begin{array}{cccc}\begin{array}{c}\text { Finland; } \\ \text { three }\end{array} & \begin{array}{c}\text { Longitudinal } \\ \text { prospective }\end{array} & \text { Three hospitals } & \text { NINCDS-ADRDA } \\ \text { criteria for AD and } \\ \text { locations } & \text { cohort } & \text { DSM-IV }\end{array}$

\section{AD 71.3\% \\ VD $11.3 \%$ \\ LBD/FTD $7.5 \%$ \\ Mixed 1.3\% \\ Alcohol induced $1.3 \%$ \\ Unknown $7.5 \%$}

N/A

291

$60.175 .3 \%$

N/A

2032

$68.1 \quad 100 \%$

unnamed 


\section{Depression and burden in caregivers of people with dementia}

Waite et al. (2004)

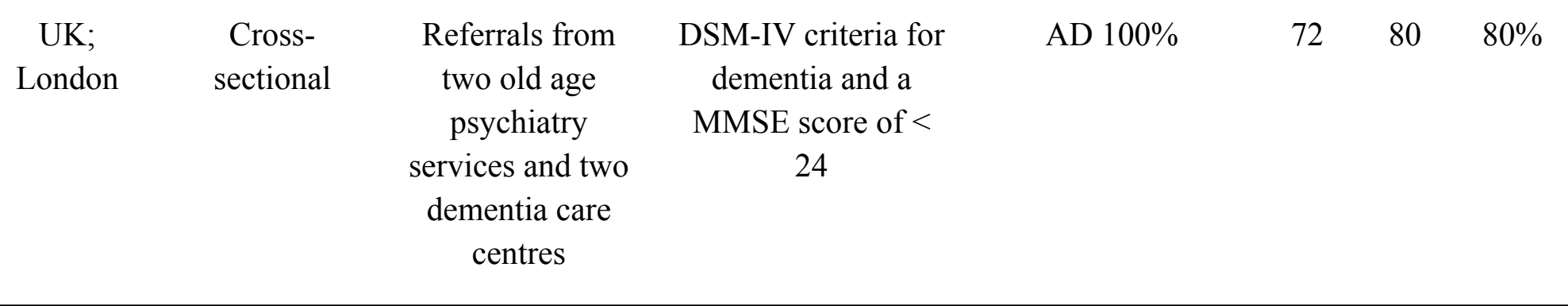


Depression and burden in caregivers of people with dementia

Table 3: Characteristics of included studies $(\mathrm{N}=43)$

\begin{tabular}{|c|c|c|c|c|c|c|c|c|}
\hline Study & Relationship & $\begin{array}{l}\text { Depression } \\
\text { measure }\end{array}$ & Cut-off & $\begin{array}{c}\text { Depression } \\
\text { prevalence \% }\end{array}$ & $\begin{array}{l}\text { Burden } \\
\text { measure }\end{array}$ & Cut-off & $\begin{array}{c}\text { Burden } \\
\text { prevalence } \%\end{array}$ & $\begin{array}{l}\text { Quality score } \\
\text { (risk) }\end{array}$ \\
\hline Adams et al. (2002) & Spouse $100 \%$ & OAHMQ & $>11$ & $30.2 \%$ & $\mathrm{~N} / \mathrm{A}$ & $\mathrm{N} / \mathrm{A}$ & $\mathrm{N} / \mathrm{A}$ & 5 (high) \\
\hline Arango et al. (2009) & $\begin{array}{c}\text { Spouse } 54.8 \% \\
\text { Child } 41.1 \% \\
\text { Other relative } \\
4.1 \%\end{array}$ & PHQ-9 & $>5$ & $39.7 \%$ & $\begin{array}{l}\text { ZBI-22 } \\
\text { item }\end{array}$ & $\geq 21$ & $68.5 \%$ & 5 (high) \\
\hline Bednarek et al. (2016) & $\begin{array}{c}\text { Spouse } 43.9 \% \\
\text { Child } 29.3 \% \\
\text { Other relative } \\
26.8 \%\end{array}$ & CES-D & $\geq 16$ & $39 \%$ & $\mathrm{~N} / \mathrm{A}$ & $\mathrm{N} / \mathrm{A}$ & $\mathrm{N} / \mathrm{A}$ & 6 (high) \\
\hline Bejjani et al. (2016) & Unknown & CES-D & $\geq 16$ & $13.6 \%$ & $\mathrm{~N} / \mathrm{A}$ & $\mathrm{N} / \mathrm{A}$ & $\mathrm{N} / \mathrm{A}$ & 5 (high) \\
\hline
\end{tabular}


Depression and burden in caregivers of people with dementia

\begin{tabular}{|c|c|c|c|c|c|c|c|c|}
\hline Berger et al. (2005) & $\begin{array}{c}\text { Spouse } 69 \% \\
\text { Child } 27 \% \\
\text { Other } 4 \%\end{array}$ & $\begin{array}{c}\text { BDI \& } \\
\text { GDS 15-item }\end{array}$ & $\begin{array}{l}>10 \\
\geq 5\end{array}$ & $26.3 \%$ & N/A & N/A & N/A & 7 (medium) \\
\hline Borsje et al. (2016) & $\begin{array}{c}\text { Spouse } 65 \% \\
\text { Child } 29.1 \% \\
\text { Other } 5.9 \%\end{array}$ & CES-D & $\geq 16$ & $23.1 \%$ & N/A & N/A & N/A & 8 (medium) \\
\hline Brodaty et al. (2014) & $\begin{array}{c}\text { Spouse } 71.2 \% \\
\text { Child } 21.7 \% \\
\text { Other } 7.1 \%\end{array}$ & N/A & N/A & N/A & $\begin{array}{c}\text { ZBI-22 } \\
\text { item }\end{array}$ & $\geq 21$ & $50 \%$ & 8 (medium) \\
\hline Cheng et al. (2013) & $\begin{array}{c}\text { Spouse } 32 \% \\
\text { Child } 59 \% \\
\text { Other relative } \\
8 \%\end{array}$ & HRSD & $>6$ & $27.5 \%$ & N/A & N/A & $\mathrm{N} / \mathrm{A}$ & 9 (medium) \\
\hline
\end{tabular}




\begin{tabular}{|c|c|c|c|c|c|c|c|c|}
\hline Contador et al. (2012) & $\begin{array}{c}\text { Spouse } 28.5 \% \\
\text { Child } 51.5 \% \\
\text { Other relative } \\
20 \%\end{array}$ & GADS & $>2$ & $36.2 \%$ & N/A & N/A & N/A & 11 (low) \\
\hline Covinsky et al. (2003) & $\begin{array}{c}\text { Spouse } 50.5 \% \\
\text { Child } 36.7 \% \\
\text { Other } 12.9 \%\end{array}$ & GDS 15-item & $\geq 6$ & $32 \%$ & N/A & N/A & N/A & 7 (medium) \\
\hline Cucciare et al (2010) & $\begin{array}{c}\text { Spouse } 23.5 \% \\
\text { Daughter, } \\
\text { daughter-in-law } \\
\text { and } \\
\text { granddaughter } \\
76.5 \%\end{array}$ & $\begin{array}{l}\text { Interview, } \\
\text { SCID-I for } \\
\text { DSM-IV }\end{array}$ & N/A & $16.9 \%$ & N/A & N/A & N/A & 7 (medium) \\
\hline Gallagher et al (2011) & $\begin{array}{c}\text { Spouse } 64.3 \% \\
\text { No other details } \\
\text { specified }\end{array}$ & CES-D-10 & $\geq 10$ & $33.3 \%$ & N/A & N/A & N/A & 6 (high) \\
\hline
\end{tabular}


Depression and burden in caregivers of people with dementia

\begin{tabular}{|c|c|c|c|c|c|c|c|c|}
\hline $\begin{array}{l}\text { García-Alberca et al } \\
\text { (2012) }\end{array}$ & $\begin{array}{c}\text { Spouse } 38.8 \% \\
\text { Child } 43.8 \% \\
\text { Sibling } 7.4 \% \\
\text { Other relative } \\
10 \%\end{array}$ & $\begin{array}{c}\text { BDI Spanish } \\
\text { version }\end{array}$ & $>20$ & $53.7 \%$ & N/A & N/A & N/A & 8 (medium) \\
\hline Germain et al. (2009) & $\begin{array}{c}\text { Spouse } 52.2 \% \\
\text { Child } 36.7 \% \\
\text { Friend } 2.00 \% \\
\text { Other } 9.1 \%\end{array}$ & N/A & N/A & N/A & ZBI-22item & $\geq 21$ & $45 \%$ & 9 (medium) \\
\hline Givens et al. (2014) & $\begin{array}{c}\text { Spouse } 63.6 \% \\
\text { No other details } \\
\text { specified }\end{array}$ & CES-D & $\geq 16$ & $22.8 \%$ & N/A & N/A & N/A & 5 (high) \\
\hline Holland et al. (2010) & $\begin{array}{c}\text { Spouse } 39 \% \\
\text { Daughters 54\% } \\
\text { Daughter-in- } \\
\text { law 7\% }\end{array}$ & CES-D & $\geq 16$ & $46.8 \%$ & N/A & N/A & N/A & 9 (medium) \\
\hline
\end{tabular}


Jang et al. (2004)

Kaiser and Panegyres (2007)

Kurz et al. (2003)

Liang et al. (2016)

Lowery et al. (2000)
Spouse 100\%

GDS

Spouse $100 \%$

BDI

$>10$

$57 \%$

N/A

N/A

$\mathrm{N} / \mathrm{A}$

7 (medium)

Spouse $53.6 \%$

Child 26.6\%

Sibling 3.9\%

Other $15.8 \%$

N/A

Chinese

version

$\begin{array}{cc}\text { Spouse } 44 \% & \text { MADRS, } \\ \text { Child } 40 \% & \text { interview } \\ \text { Other relative } & \text { and RDC }\end{array}$

$16 \%$

criteria
HADS

$\geq 8$

$\geq 5$ form

$42.6 \%$

N/A

N/A

N/A

6 (high)

$20.9 \%$

N/A

N/A

N/A

6 (high)

N/A

$3 \%$

N/A

N/A

N/A

5 (high) 
Depression and burden in caregivers of people with dementia

\begin{tabular}{|c|c|c|c|c|c|c|c|c|}
\hline Lu and Austrom (2005) & $\begin{array}{c}\text { Spouse } 75.3 \% \\
\text { Child } 19.6 \% \\
\text { Daughter-in- } \\
\text { law } 3.1 \% \\
\text { Other } 2 \%\end{array}$ & CES-D & $\geq 16$ & $28.9 \%$ & $\mathrm{~N} / \mathrm{A}$ & N/A & $\mathrm{N} / \mathrm{A}$ & 6 (high) \\
\hline Luchsinger et al. (2015) & $\begin{array}{c}\text { Spouse } 38.8 \% \\
\text { Child } 56.8 \% \\
\text { Other } 4.3 \%\end{array}$ & GDS & $\geq 10$ & $51.1 \%$ & $\begin{array}{l}\text { ZBI-22 } \\
\text { item }\end{array}$ & $\geq 21$ & $88.5 \%$ & 8 (medium) \\
\hline Mahoney et al. (2005) & $\begin{array}{c}\text { Spouse } 44.4 \% \\
\text { Child } 44.4 \% \\
\text { Friends } 4.6 \% \\
\text { Other relative } \\
6.6 \%\end{array}$ & HADS & $\geq 11$ & $10.5 \%$ & $\mathrm{~N} / \mathrm{A}$ & N/A & $\mathrm{N} / \mathrm{A}$ & 9 (medium) \\
\hline $\begin{array}{l}\text { McConaghy and } \\
\text { Caltabiano (2005) }\end{array}$ & $\begin{array}{c}\text { Spouse } 54.8 \% \\
\text { Child } 35.7 \\
\text { Friends } 2.4 \% \\
\text { Other relative } \\
7.1 \%\end{array}$ & CES-D & $\geq 16$ & $59.5 \%$ & $\begin{array}{c}\text { ZBI-22 } \\
\text { item }\end{array}$ & $\geq 21$ & $78.6 \%$ & 7 (medium) \\
\hline
\end{tabular}


Depression and burden in caregivers of people with dementia

\begin{tabular}{|c|c|c|c|c|c|c|c|c|}
\hline Medrano et al. (2014) & $\begin{array}{c}\text { Spouse } 15 \% \\
\text { Child } 55 \% \\
\text { Grandchild } 12 \% \\
\text { Brother } 9 \% \\
\text { Other relative } \\
9 \%\end{array}$ & $\begin{array}{l}\text { HRSD } \\
\text { Spanish } \\
\text { Version }\end{array}$ & $>8$ & $43.3 \%$ & $\begin{array}{l}\text { ZBI-22 } \\
\text { item } \\
\text { Spanish } \\
\text { version }\end{array}$ & $\geq 46$ & $35.8 \%$ & 7 (medium) \\
\hline $\begin{array}{l}\text { Orgeta and Lo Sterzo } \\
\text { (2013) }\end{array}$ & $\begin{array}{c}\text { Spouse } 52.6 \% \\
\text { Child } 29.3 \% \\
\text { Other relative } \\
18.1 \%\end{array}$ & HADS & $\geq 8$ & $54.7 \%$ & N/A & $\mathrm{N} / \mathrm{A}$ & N/A & 6 (high) \\
\hline Ostojic et al. (2014) & $\begin{array}{c}\text { Spouse } 26.7 \% \\
\text { Child } 63.3 \%\end{array}$ & $\begin{array}{c}\text { HADS } \\
\text { Croatian } \\
\text { translation }\end{array}$ & $\geq 11$ & $26.7 \%$ & N/A & $\mathrm{N} / \mathrm{A}$ & N/A & 5 (high) \\
\hline Raggi et al. (2015) & $\begin{array}{c}\text { Spouse } 57.5 \% \\
\text { Child } 38.4 \% \\
\text { Sibling } 2.7 \% \\
\text { Nephew } 1.4 \%\end{array}$ & N/A & $\mathrm{N} / \mathrm{A}$ & N/A & CBI & $>24$ & $60.3 \%$ & 5 (high) \\
\hline
\end{tabular}


Depression and burden in caregivers of people with dementia

\begin{tabular}{|c|c|c|c|c|c|c|c|c|}
\hline Riedel et al. (2016) & $\begin{array}{c}\text { Spouse } 48.5 \% \\
\text { Child } 36.3 \% \\
\text { Son-in- } \\
\text { law/daughter- } \\
\text { in-law 5.5\% } \\
\text { Other } 9.4 \%\end{array}$ & DSQ & $\geq 10$ & $43.7 \%$ & $\mathrm{~N} / \mathrm{A}$ & N/A & $\mathrm{N} / \mathrm{A}$ & 10 (low) \\
\hline Rosness et al. (2011) & Spouse $100 \%$ & GDS-15 item & $\geq 5$ & $53.1 \%$ & $\mathrm{~N} / \mathrm{A}$ & $\mathrm{N} / \mathrm{A}$ & $\mathrm{N} / \mathrm{A}$ & 7 (medium) \\
\hline Roth et al. (2008) & $\begin{array}{c}\text { Spouse } 48.2 \% \\
\text { Child } 41.8 \% \\
\text { Other } 10.1 \%\end{array}$ & CES-D & $\geq 16$ & $41 \%$ & $\mathrm{~N} / \mathrm{A}$ & N/A & $\mathrm{N} / \mathrm{A}$ & 7 (medium) \\
\hline
\end{tabular}


Depression and burden in caregivers of people with dementia

Sansoni et al. (2014)

Simpson (2010)

Slachevsky et al. (2013)

$$
\begin{gathered}
\text { Spouse } 40 \% \\
\text { Child } 43 \% \\
\text { Sibling 5\% } \\
\text { Relative in law } \\
4 \% \text { Friends } 1 \%
\end{gathered}
$$

Sleath et al. (2005) Sister $1.94 \%$

$$
\text { Daughter }
$$

$11.76 \%$ Friend

$2.94 \%$ Other relative $8.82 \%$

Spouse $50.1 \%$

Child $41.3 \%$

Other 6.3\%
GDS

N/A

N/A

N/A

$\begin{array}{cc}\text { Spouse } 92 \% & \text { CES-D } \\ \text { Sister and } & \text { modified } \\ \text { daughter } 8 \% & \text { version }\end{array}$

$\geq 9$

$31 \%$
ZBI-22
item

Chilean

version

N/A

N/A

6 (high)

N/A

N/A

N/A

9 (medium) 


\begin{tabular}{|c|c|c|c|c|c|c|c|c|}
\hline Valimaki et al. (2015) & $\begin{array}{c}\text { Spouse } 70.24 \% \\
\text { Non-spouse } \\
29.76 \%\end{array}$ & BDI & $>10$ & $44.1 \%$ & $\mathrm{~N} / \mathrm{A}$ & N/A & $\mathrm{N} / \mathrm{A}$ & 7 (medium) \\
\hline Waite et al. (2004) & $\begin{array}{l}\text { Spouse } 45.8 \% \\
\text { Daughters } \\
31.9 \% \text { Friends } \\
\text { or other } \\
\text { relatives } 22.5 \%\end{array}$ & GDS-15 item & $\geq 5$ & $43.1 \%$ & $\mathrm{~N} / \mathrm{A}$ & $\mathrm{N} / \mathrm{A}$ & $\mathrm{N} / \mathrm{A}$ & 6 (high) \\
\hline
\end{tabular}

Note: $\mathrm{N} / \mathrm{A}=$ not available. Location: $\mathrm{AL}=$ Alabama; $\mathrm{CA}=$ California; $\mathrm{FL}=$ Florida; $\mathrm{IL}=$ Illinois; $\mathrm{MA}=$ Massachusetts; $\mathrm{MN}=\mathrm{Minnesota} ; \mathrm{NY}$ $=$ New York; OH = Ohio; OK = Oklahoma; OR = Oregon; PA = Pennsylvania; RI = Rhode Island; $\mathrm{TN}=$ Tennessee; TX = Texas; UK = United Kingdom; USA = United States of America; UT = Utah. Design: RCT $=$ Randomized Controlled Trial. Recruitment source: USC $=$ University of Southern California. Dementia diagnostic tools: CAMDEX = Cambridge Mental Disorders of the Elderly Examination (Roth et al., 1986); CDRS = Clinical Dementia Rating Scale (Hughes, Berg, Danziger, Coben \& Martin, 1982); DSM-III-R/IV/IV-R/5 = Diagnostic and Statistical Manual of Mental Disorders third edition revised (APA, 1987)/fourth edition (APA, 1994)/ fourth edition revised (APA, 2000)/fifth edition revised (APA, 2013); ICD-9/10 = International Statistical Classification of Diseases and Related Health Problems- $9^{\text {th }}$ Revision $($ WHO, 1978) $/ 10^{\text {th }}$ Revision (WHO, 1992); ICPC-2 = International Classification of Primary Care-Second Edition (WHO, 2003); MMSE = Mini Mental State Exam (Folstein, Folstein \& McHugh, 1975); NINCDS-ADRDA = National Institute of Neurological and Communicative Disorders and Stroke and the Alzheimer's Disease and Related Disorders Association (McKhann et al., 1984). Dementia terms: AD = Alzheimer's Disease; FTD $=$ Frontotemporal Lobe Dementia; DLB = Dementia with Lewy Bodies; PPA = Primary Progressive Aphasia; PwD = people with dementia; VD = Vascular Dementia. Depression measures: BDI-I/short form/II/Spanish Version/Chilean Version = Beck Depression Inventory (Beck et al., 1961)/short-form (Beck \& Beck,1972)/second edition (Beck, Steer, Ball \& Ranieri, 1996)/Spanish Version (Conde \& Useros, 1975)/Chilean Version; CES-D/-10/modified version = Centre for Epidemiological Studies-Depression (Radloff 1977)/10-item (Andresen, Malmgren, Carter, \& Patrick, 1994)/modified version (Hays, Blazer \& Gold, 1993); DSQ = Depression Screening Questionnaire (Wittchen, Höfler, \& Meister, 2001); GADS = Goldberg Anxiety and Depression Scale (Goldberg, Bridges, Duncan-Jones, \& Grayson, 1988); GDS/-15item $=$ Geriatric Depression Scale (Yesavage et al., 1983)/15-item (Yesavage \& Sheikh, 1986); HADS original/Chinese Version = Hospital Anxiety and Depression Scale (Zigmond \& Snaith, 1983)/-Chinese Version (Chan, Leung, Fong, Leung, \& Lee, 2010); HRSD/-Spanish version 
= Hamilton Rating Scale for Depression (Hamilton, 1980)/-Spanish version (Ramos-Brieva, 1986); MADRS = Montgomery Asberg Depression Rating Scale (Montgomery \& Asberg, 1979); PHQ-9 = Patient Health Questionnaire-9 (Kroenke, Spitzer \& Williams, 2001); OAMHQ = The Older Adult Health and Mood Questionnaire (Kemp and Adams, 1995); SCID-I = Structured Clinical Interview for DSM-IV Axis I Disorders (First, Spitzer, Gibbon, \& Williams, 2008); RDC = Research Diagnostic Criteria (Spitzer \& Robins, 1978). Burden measures: ZBI 22item/Spanish version/Chilean version = Zarit Burden Interview (Zarit et al., 1980)/Spanish version (Martín et al., 1996)/Chilean Version (Breinbauer et al., 2009); CBI = Caregiver Burden Inventory (Novak \& Guest, 1989). 